\title{
Small heat-shock proteins: important players in regulating cellular proteostasis
}

Teresa M. Treweek ${ }^{\mathrm{a}, \mathrm{b}}$, Sarah Meehan ${ }^{\mathrm{c}}$, Heath Ecroyd ${ }^{\mathrm{b}, \mathrm{d}}$ and John A. Carver ${ }^{\mathrm{e}}$.

a Graduate School of Medicine, University of Wollongong, Northfields Avenue, Wollongong, NSW 2522, Australia

b Illawarra Health and Medical Research Institute, Northfields Avenue, Wollongong, NSW 2522, Australia

c Department of Chemistry, The University of Cambridge, Lensfield Road, Cambridge CB2 1EW, United Kingdom

d School of Biological Sciences, University of Wollongong, Northfields Avenue, Wollongong, NSW 2522, Australia

e Research School of Chemistry, The Australian National University, Canberra, ACT 0200, Australia

e Corresponding authors:

Email: john.carver@anu.edu.au; Tel: +61 26125 9748; Fax: +61 261250750

Email: heathe@uow.edu.au; Tel: +61242213443

\author{
Abbreviations \\ A $\beta$ : amyloid $\beta$ \\ $\alpha$ Ac: $\alpha$ A-crystallin \\ $\alpha \mathrm{Bc}: \alpha \mathrm{B}$-crystallin \\ $\alpha c: \alpha$-crystallin \\ ACD: $\alpha$-crystallin domain \\ AD: Alzheimer's disease \\ ALS: Amylotrophic Lateral Sclerosis \\ $\alpha$-syn: $\alpha$-synuclein \\ CJD: Creutzfeldt-Jakob disease \\ CMT: Charcot-Marie-Tooth disease \\ cryo-EM: cryo-electron microscopy \\ DRM: desmin-related myopathy \\ GAFP: glial acidic fibrillary protein \\ HMN: hereditary motor neuropathy \\ Hsp: heat-shock protein \\ MS: Multiple sclerosis \\ PD: Parkinson's disease \\ $\mathrm{PrP}^{\mathrm{sc}}$ : prion protein \\ SANS: small-angle neutron scattering \\ SAXS: small-angle X-ray scattering \\ sHsp: small heat-shock protein \\ TEM: Transmission Electron Microscopy
}

\section{Keywords}

Small heat-shock protein, sHsp, molecular chaperone, proteostasis, cataract, neurodegenerative disease

\section{Running Title}

Small heat-shock proteins regulate cellular proteostasis 


\section{Abstract}

Small heat-shock proteins (sHsps) are a diverse family of intracellular molecular chaperone proteins that play a critical role in mitigating and preventing protein aggregation under stress conditions such as elevated temperature, oxidation and infection. In doing so, they assist in the maintenance of protein homeostasis (proteostasis) thereby avoiding the deleterious effects that result from loss of protein function and/or protein aggregation. The chaperone properties of sHsps are therefore employed extensively in many tissues to prevent the development of diseases associated with protein aggregation. Significant progress has been made of late in understanding the structure and chaperone mechanism of sHsps. In this review, we discuss some of these advances, with a focus on mammalian sHsp hetero-oligomerisation, the mechanism by which sHsps act as molecular chaperones to prevent both amorphous and fibrillar protein aggregation, and the role of post-translational modifications in sHsps chaperone function, particularly in the context of disease. 


\section{Introduction}

The proteome is inherently meta-stable [1,2]. Arguably, the most important means nature uses to maintain the integrity of the proteome (termed proteostasis) is the network of molecular chaperone proteins, which are present both intra- and extracellularly. The abundant and ubiquitous small heat-shock proteins (sHsps) are a family of intracellular molecular chaperones that interact with partially folded target proteins to stabilise and prevent their aggregation and precipitation. They do so under constitutive conditions but many sHsps are particularly prevalent under stress conditions when their expression is significantly up-regulated. The sHsps have a wide tissue distribution and, as a result, are associated with a plethora of disease states, particularly those related to compromised proteostasis (e.g. involving defective protein folding). In the eye lens, for example, the high concentration of the two major sHsps, $\alpha \mathrm{A}$ - and $\alpha \mathrm{B}$-crystallin, prevents protein aggregation, in addition to ensuring proper lens transparency. Recently, excellent reviews on the structure and functions of various sHsps have been published, all aimed at contributing to and better describing their as yet ill-defined mode of chaperone action and their roles in physiological and pathological processes [3-7]. As stated by Mymrikov et al.[5], 'the amount of information in this field is accumulating very rapidly' as we draw incrementally closer to the practical application of this knowledge in the prevention and treatment of disease. In this review, we summarise recent research into sHsp structure, function and interactions. Following a brief introduction to the structure and chaperone action of sHsps, we focus on the importance of hetero-oligomerisation and post-translational modification (primarily phosphorylation) to sHsp chaperone action and the ability of members of this protein family to successfully stabilise target proteins undergoing either amorphous or fibrillar aggregation. In the context of their impacts on normal chaperone function, we also examine the effects of naturally-occurring sHsp mutations that result in human diseases such as cataract, peripheral myopathies and neurodegenerative diseases.

Since sHsps are intracellular molecular chaperones, this review focusses on the ability of sHsps to mitigate and prevent protein aggregation inside the cell. However, protein aggregation also occurs in the extracellular environment where there is a set of molecular chaperones that function to minimise the deleterious effects of protein aggregation (recently reviewed in [8]). The best characterised extracellular molecular chaperone is clusterin, which was also the first to be described [9]. Clusterin, like the other extracellular chaperones, is unrelated to the sHsps, yet it functions in a very similar chaperone manner to the sHsps to prevent protein aggregation [10]. 


\section{SECTION I: The structure and function of sHsps}

Each sHsp is comprised of three regions: $\mathrm{N}$ - and C-terminal regions which are separated by a highly conserved $\alpha$-crystallin domain (ACD) of approximately 80 amino acids in length that is a defining characteristic of all sHsps (Figure 1A). By contrast, the $\mathrm{N}$ - and C-terminal flanking regions are variable in length between the sHsps and lack significant sequence similarity. The structures of mammalian sHsps have proved difficult to decipher. Of late, a battery of powerful and complementary techniques, i.e. X-ray crystallography, solid-state and solution NMR spectroscopy, small-angle X-ray scattering (SAXS), small-angle neutron scattering (SANS), mass spectrometry and cryo- and transmission electron microscopy (cryo-EM and TEM, respectively) have been utilised to gain unprecedented insight into the structure of sHsps. We shall only discuss the salient structural features that have become apparent from these studies as more in-depth discussion has been presented in recent reviews of sHsp structure $[3,7,11,12]$.

The subunit monomeric mass of sHsps ranges from 15 to $40 \mathrm{kDa}$, however their classification (and nomenclature) as sHsps is somewhat of a misnomer as they typically exist as large, spherical, oligomeric species in solution. In the case of $\alpha \mathrm{Bc}$, these oligomers are highly heterogeneous with a mass range under physiological conditions, as determined by light scattering, of $420-980 \mathrm{kDa}$ [13] and an average mass of approximately $650 \mathrm{kDa}$ [14]. Moreover, sHsps are highly dynamic species as there is extensive subunit exchange between oligomers which may be important in their chaperone function [15]. In addition, the dynamic nature of sHsps is also due to large portions, particularly within the $\mathrm{N}$ - and C-terminal regions, having little well-defined secondary structure and exhibiting flexibility. The extreme C-terminus, within the $\mathrm{C}$-terminal region, is very much so with solution-phase NMR spectroscopy revealing that the last 10 and 12 amino acids in $\alpha \mathrm{Ac}$ and $\alpha \mathrm{Bc}$ respectively are unstructured C-terminal extensions that have mobility comparable to isolated peptides of the same length [16-19]. Similarly, other mammalian sHsps have highly flexible C-terminal extensions [17,18]. The heterogeneity, dynamism and flexibility of mammalian sHsps have inhibited crystallisation attempts of the full-length proteins, however X-ray crystal structures are available for some non-mammalian sHsps which lack the flexible C-terminal extensions and form well-ordered oligomers, e.g. of Hsp16.5, a 24-mer from a hyperthermophilic archeon Methanococcus jannaschii [20] (Fig. 1B) and Hsp16.9, a 12-mer from wheat [21].

There is much evidence, e.g. from X-ray crystallography and mass spectrometry [22], that the building block of the sHsp oligomer is a dimer. The crystal structures of the isolated ACD from $\alpha \mathrm{Bc}$ [23], Hsp27 [24] and Hsp20 
[23] have confirmed this dimer arrangement and the predicted features of this domain, i.e. that it is highly $\beta$-sheet in character and arranged in an immunoglobulin-like fold. Structures of the ACD of $\alpha \mathrm{Ac}$ and $\alpha \mathrm{Bc}$ that also contained the majority of the C-terminal region, but not the C-terminal extension, were recently solved [25]. These structures demonstrated that a $\beta$-strand (numbered 6 and 7) from each monomer, via an anti-parallel arrangement, provides the inter-subunit (i.e. intra-dimer) interface [25](Fig. 1C). Furthermore, the conserved I-X-I motif(I159$\mathrm{P} 160-\mathrm{I} 161$ in $\alpha \mathrm{Bc}$ ) in the $\mathrm{C}$-terminal region of one subunit can bind in a groove formed between the $\beta 4$ and $\beta 8$ strands on a subunit of an adjacent dimer, forming the inter-dimer interface [26] (Fig. 1C). The I-X-I motif is the central part of a nine amino acid palindromic sequence that enables equivalent interactions in both directions of the polypeptide chain with other subunits. As a result, this region facilitates polydisperse oligomerisation. Crystal formation is deleterious to lens transparency and this palindromic sequence may be the crucial factor in inhibiting $\alpha \mathrm{Bc}$ crystallisation and in enabling dynamic interactions both with itself (via subunit exchange) and its target protein during chaperone action.

In agreement with the X-ray crystallographic studies, a solution and solid-state NMR and SAXS investigation of full-length $\alpha \mathrm{Bc}$ concluded that the ACD adopts an immunoglobulin-like $\beta$-sheet structure [27]. Subsequent solidstate NMR studies concluded that the N-terminal flanking region has two short helices and a small stretch of antiparallel $\beta$-sheet near the boundary with the ACD [28]. The heterogeneity of NMR resonances, however, implied that significant conformational mobility exists in the N-terminal region. From these data, in combination with TEM and SAXS measurements, a model for the quaternary arrangement of $\alpha \mathrm{Bc}$ was constructed based around a core 24-mer to which dimers can be added [28].

On this latter point, the quaternary structure of $\alpha \mathrm{Bc}$ has been studied for many years, yet there is no agreement as to the precise quaternary arrangement of mammalian sHsp oligomers with various models proposed (summarised in [29]). Cryo-EM studies show that under physiological conditions, the human $\alpha \mathrm{Bc}$ oligomer forms large roughly spherical assemblies of $8-18 \mathrm{~nm}$ in diameter $[14,30]$. Under partially denaturing conditions and elevated temperature, $\alpha \mathrm{Bc}$ also assembles into amyloid fibrils as revealed by TEM and atomic force microscopy [31,32]. Cryo-EM reconstructions applied to native $\alpha \mathrm{Bc}$ oligomers suggest a dynamic and variable asymmetric quaternary structure, with a roughly spherical protein shell of average diameter $\sim 15 \mathrm{~nm}$ which surrounds a large central cavity of $\sim 8 \mathrm{~nm}$ in diameter $[14,30,33]$. The oligomer is characterised by having large openings in the shell leading to 
the interior [34]. A large central cavity is characteristic of sHspoligomers (Fig. 1B), as was predictedfrom simple consideration of polypeptide occupancy within such oligomers [35].

\section{$\alpha$-Crystallin in the lens}

In humans, there are ten sHsps (HSPB1-10), the predominant being $\alpha \mathrm{A}$-crystallin ( $\alpha \mathrm{Ac}, \mathrm{HSPB} 4), \alpha \mathrm{B}$-crystallin ( $\alpha \mathrm{Bc}, \mathrm{HSPB} 5), \mathrm{Hsp} 27$ (HSPB1) and Hsp20 (HSPB6). $\alpha$-Crystallin $(\alpha c)$, the complex between $\alpha \mathrm{Ac}$ and $\alpha \mathrm{Bc}$ subunits (at a 3:1 molar ratio of $\alpha \mathrm{Ac}$ to $\alpha \mathrm{Bc}$ in humans [36]) that is present in the eye lens, along with the other crystallins ( $\beta$ and $\gamma$ ), form a concentrated, closely associated and ordered array that enables proper refraction of light through the lens and its focusing onto the retina. $\alpha \mathrm{C}$ is the principal lens protein and, like its individual subunits, $\alpha \mathrm{c}$ forms large, heterogeneous, oligomeric and dynamic complexes, in this case of $\sim 160$ to $1,000 \mathrm{kDa}$ in mass $[22,30,37]$. X-ray and neutron solution scattering experiments have shown that $\alpha c$ increases in size

significantly at higher temperature [38-42] such that the radius of gyration changes from $69 \pm 3 \AA$ to $81 \pm 5 \AA$ following incubation at $65^{\circ} \mathrm{C}$ [40]. This change is not reversed by cooling, in contrast to the behaviour of $\alpha \mathrm{c}$ at high pressure where reversibility is observed [42]. Neutron scattering experiments of complexes formed between $\alpha c$ and $\gamma \mathrm{E}$-crystallin at high temperature $\left(65^{\circ} \mathrm{C}\right)$ demonstrated that the latter binds inside the central cavity of $\alpha \mathrm{c}$ [40] most likely becoming more surface-exposed at higher temperature due to major structural rearrangements (including partial unfolding) that occur to $\alpha \mathrm{c}$ at these temperatures leading to exposure of the core of the oligomer. Access to the core would be facilitated by the porous nature of the $\alpha c$ oligomer [34], i.e. the presence onits surface of openings or 'fenestrations' [39]. Interestingly, under milder stress conditions, target proteins are probably located in the 'fenestrations' rather than inside the oligomer cavity [39,43] implying that $\alpha \mathrm{chas}$ a variety of modes of interaction with target proteins, depending on the stress conditions.

For many years, $\alpha \mathrm{c}$ was regarded as simply a 'filler' protein that was only found in the lens in high concentrations to ensure proper lens transparency. This situation is certainly not true nowadays. Major research interest in $\alpha c$ (and sHsps in general) was sparked by two seminal observations: (1) Bhat and Nagineni's finding [44] that $\alpha \mathrm{Bc}$ is present in many non-lens tissues and (2) Horwitz's identification of the molecular chaperone activity of ac whereby it prevents the aggregation and precipitation of a diversity of proteins under stress conditions, e.g. elevated temperature [45]. Horwitz's observation was an experimental verification of Ingolia and Craig's earlier classification of $\alpha \mathrm{c}$ as a member of the sHsp molecular chaperone family [46]. In the lens, the chaperone ability 
of $\alpha c$ is of paramount importance in that it prevents the aggregation and precipitation of the crystallin proteins and hence delays the onset of age-related cataract. In this section we will discuss the role of $\alpha \mathrm{c}$ in the lens. $\alpha \mathrm{C}$ possesses two interlinking characteristics within the eye lens that are crucial to maintaining lens transparency and hence visual acuity, namely its structural organisation and its chaperone activity. Firstly, however, it is helpful to describe the unusual environment of the lens to gain a further appreciation of the importance of $\alpha$ c's biological role in this tissue. The avascular eye lens, surrounded by a collagen rich capsule, is composed of fibre cells, which develop from the single layer of epithelial cells on the anterior surface of the lens [47]. The lens fibre cells undergo a differentiation process involving cell elongation, expression of the predominant lens proteins, the crystallins [48], and degradation of cellular organelles, including the removal of nuclei [47,49-51]. This loss of cellular organelles is thought to aid lens transparency, by removing potentially light scattering structures from the light path [50]. Lens transparency is limited by absorption and scattering of visible light. Visible light absorption is usually negligible for eye lenses since the electronic energy level separations of proteins in general, and thus including the crystallins, are too great to enable molecules to be promoted to the excited state upon irradiation by visible light. Lens transparency is thus determined by scattering of light by the lens cytoplasm protein solution [52].

Crystallin protein concentration has been estimated at approximately $200 \mathrm{mg} / \mathrm{mL}$ in the outer lens cortex, and up to $460 \mathrm{mg} / \mathrm{mL}$ in the central lens nucleus [53,54]. Despite this extremely high protein concentration and high degree of organisation in the lens, the crystallin proteins do not crystallise, and are free to move [52]. The crystallins are organised in a highly stable supramolecular $\beta$-sheet structure within the lens [55-57]. Lens transparency is proposed to be maintained by a liquid-like, short-range order in the highly concentrated crystallin solutions, as found in dense liquids or glasses [58]. $\alpha \mathrm{C}$ comprises $30-40 \% \mathrm{w}$ : $\mathrm{w}$ of the lens soluble protein [33,59], and is thus a key player in this highly organised structural array.

The loss of cellular organelles in the lens renders the lens fibre cells incapable of protein synthesis, hence there is almost no protein turnover in the lens. Consequently, the crystallin proteins must be maintained in a stable state throughout the lifespan of the organism. The chaperone action of $\alpha \mathrm{c}$ in preventing the aggregation of itself and $\beta$ and $\gamma$-crystallins [45,60-62] is therefore especially important in the lens given the absence of cellular organelles and lack of new protein production. Indeed, it has been proposed that the reason for the predominance of $\alpha \mathrm{Ac}$ over $\alpha \mathrm{Bc}$ in the lens is that $\alpha \mathrm{Ac}$ acts as a chaperone for $\alpha \mathrm{Bc}$, which is intrinsically less stable than $\alpha \mathrm{Ac}[60,63]$. 


\section{Expression and function of sHsps extra-lenticularly}

Bhat and Nagineni's [44] and Horwitz's [45] discoveries are highly interconnected: the extensive extra-lenticular expression of $\alpha \mathrm{Bc}$ and other sHsps unquestionably arises from their fundamental chaperone activity, i.e. nature has utilised their activity in many and varied roles in cells in order to maintain proteostasis. In addition to the lens, $\alpha \mathrm{Bc}$ is also located in many parts of the body and is found at high levels in the retina, heart, skeletal muscle, skin, brain, spinal cord, kidneys, lungs [44,64,65], the cochleae of the mammalian ear [66], and the lacrimal gland duct and tears [67]. $\alpha$ Ac is present, albeit to a much lesser extent, for example in the spleen and thymus [68]. Outside of the lens, $\alpha \mathrm{Bc}$ has a wide variety of metabolic and regulatory functions [69,70]; expression is induced by stress, for example by $\mathrm{pH}$ extremes, elevated temperature, chemical or heavy metal exposure, or hypertonic stress [7173] and this confers both thermotolerance [74] and protection against oxidative stress to cells [75,76].

Many of the other members of the sHsp family exhibit wide extra-lenticular tissue distribution with Hsp20, for example, being constitutively and highly expressed in all types of muscle [6]. Hsp22 (HSPB8), Hsp27 and $\alpha$ Bc are also present in muscle cells, along with being expressed in many other cell types including neurons [6]. The extra-lenticular expression of the major sHsps is summarized in Table 1.

Outside the lens, the sHsps play a vital role in maintaining cell viability under stress conditions: they can reach levels of up to $1 \%$ of the total cellular protein pool following stress and they are the most acutely induced of the heat-shock proteins (Hsps). Moreover, the sHsps are an integral component of the proteostasis network in cells and their chaperone (mal)function and/or over-expression is associated with many diseases, e.g. neurodegenerative diseases, various cancers, cataract, cardiomyopathies and multiple sclerosis [77,78] (see Section III). The significance of sHsp malfunction in the context of disease is exemplified by the development of therapeutics that target expression of one sHsp, Hsp27, for the treatment of bladder, prostate and pancreatic cancers [79]. The common theme from this work is that failure of sHsps to act, through their chaperone activity, to stabilise target proteins and prevent their improper interactions in cells can cause disease.

\section{Hetero-oligomerisation of sHsps}

Whilst much work has focussed on the structure and function of homo-oligomeric forms of sHsps (see discussion above), in vivo sHsps most likely exist predominately as hetero-oligomers. For example, both Hsp27 and $\alpha \mathrm{Bc}$ are expressed in the kidneys, bladder, lungs, stomach, cardiac and skeletal muscle [73,80-82] and co-localise in both 
normal and pathological tissues of neurodegenerative patients $[80,83,84]$. Moreover, they associate, to a partial degree, with each other in these tissues [85] and in stably transfected HeLa cells expressing wild type or the disease-causing mutant R120G $\alpha \mathrm{Bc}$ [86]. Mixing of subunits is facilitated by the dynamic subunit exchange of mammalian sHsps $[15,87,88]$ and is proposed to play a functional role in chaperone action (see next section). We have recently used mass spectrometry to quantify the rate of subunit exchange from Hsp27 and $\alpha \mathrm{Bc}$ homooligomers to form hetero-oligomers, and characterise the end products [89]. The rate of subunit exchange between Hsp27 and $\alpha \mathrm{Bc}$ was more rapid than that reported for Hsp27 and $\alpha \mathrm{Ac}$, and $\alpha \mathrm{Ac}$ and $\alpha \mathrm{Bc}[87,89]$. The heterooligomers had masses and thermo-stabilities intermediate to those of the homo-oligomers and their chaperone ability was equivalent to that of $\alpha \mathrm{Bc}$ (and better than Hsp27).

To-date, there is also evidence for the formation of hetero-oligomeric complexes between $\alpha \mathrm{A}$ - and $\alpha \mathrm{Bc}$, as occurs in the lens [44,61], $\alpha \mathrm{Ac}$ and Hsp27 [87], HspB2 and HspB3 [90,91], $\alpha \mathrm{Bc}$ and Hsp20 [92] and Hsp27 and Hsp20 [88]. However, caution is required in interpreting work that has involved adding a bulky tag directly to the sHsps to measure sub-unit exchange (for example, adding green fluorescent protein or one of its derivatives for fluorescence energy transfer studies) as these can directly interfere with the dynamism of the sHsps, their ability to form oligomers and thus their chaperone function $[93,94]$. The formation of hetero-oligomers between sHsps is temperature dependent $[15,87,88,95]$ and, upon heat shock, the hetero-oligomeric assemblies of $\mathrm{Hsp} 27$ and $\alpha \mathrm{Bc}$ in cells dissociate and reform once the cell has recovered [85]. This raises questions as to whether homo- and hetero-oligomeric forms of sHsps play different functional roles in the cells. For example, variation in the subunit composition of hetero-oligomers (as opposed to homo-oligomers) may influence the interaction with and binding of target proteins and therefore facilitate interactions with some cellular components in preference to others.

\section{The chaperone mechani sm of sHsps}

The sHsps are typically classified as 'holdase' chaperones, however, this description does not fully describe the multi-faceted nature by which they can interact with target proteins to prevent their aggregation. Whilst the sHsps can bind tightly to, and form high-molecular-mass complexes with, destabilised protein intermediates to maintain them in a refolding competent state (for example, so that they are amenable to refolding by ATP-dependent chaperones such as Hsp 70, when cellular conditions permit [96]), they can also interact with target proteins in a weak and transient manner, briefly stabilising them in order to facilitate their intrinsic ability to refold back to their native (functional) state. For example, $\alpha \mathrm{Bc}$ forms stable high-molecular-mass complexes with disordered, 
precipitation-bound intermediates of the target protein $\alpha$-lactalbumin that expose significant amounts of hydrophobicity to solution but also interacts through weak, transient interactions to suppress the aggregation of relatively stable $\alpha$-lactalbumin intermediates that expose less hydrophobicity to solution [43,97-100]. The weak transient interactions with target proteins is the mechanism that most likely predominates in cells that are not subjected to stress since these conditions are not conducive to large-scale protein destabilisation. Thus, it is envisaged that sHsps only mediate stable high-molecular-mass complex formation with protein intermediates (i.e. act as 'holdases') when binding is more energetically favourable than refolding. As such, their broad mechanism of action indicates that a more apt description of sHsp chaperones is as 'stabilisers' rather than 'holdases'.

Currently, no well-defined target protein binding site(s) has been identified for mammalian sHsps. Various studies have suggested that target protein binding is mediated by the N-terminal domain [101-104] or the ACD [105107]. Indeed, with regards to the latter, we [26] and others $[25,27,108]$ have shown that isolated ACDs exhibit chaperone function. Sharma and colleagues have shown that 'mini' chaperones comprised of only residues 70-88 of $\alpha \mathrm{Ac}$ within its $\mathrm{ACD}$ and the corresponding residues (73 - 92) of $\alpha \mathrm{Bc}$ act as efficient chaperones in their own right $[105,109]$. Moreover, target protein binding may also be regulated by multiple regions of the sHsp. For example, it has been recently suggested that target protein access to a binding site formed between $\beta$-sheets 4 and 8 in $\alpha \mathrm{Bc}$ 's $\mathrm{ACD}$ is regulated by auto-inhibitory docking of the C-terminal I-X-I hinge region into this groove, i.e. at the inter-dimer interface (Fig. 1C) [29,107]. In this case, hydrophobic target proteins compete with this Cterminal region for binding at this site on $\alpha \mathrm{Bc}$. The overall emerging picture is that there is no single target protein binding site on sHsps, rather binding is mediated by hydrophobic sites on the surface of the sHsp and these sites of interaction vary depending on the sHsp and target protein in question. Intriguingly, as discussed above, the central cavity of sHsps also appears to play a role in sHsp chaperone action, for example under conditions of severe stress $[40,43,110]$.

The remarkable ability of sHsps to distinguish disordered protein intermediates from stable (native-like) intermediates is proposed to be based upon the intermediate's free energy of unfolding [111], the lifetime of the intermediate and its relative degree of exposed hydrophobicity [97]. To-date, the most widely accepted model of sHsp chaperone action is that dissociated species (normally depicted as dimers) are the more chaperone-active species and large oligomers are 'reservoirs' of these species; the dissociated species associate with target proteins and then can re-associate with the large oligomers to form high-molecular-mass sHsp-target protein complexes. 
This model is favoured because it is thought that (i) the dissociated species would expose more surface hydrophobicity to solution and therefore be more capable of binding to destabilised target proteins and, (ii) the chaperone activity of sHsps is dependent on subunit exchange. Recent work, including our own, has shed further light on the multi-faceted manner by which sHsps interact with aggregation-prone proteins, particularly those aggregating to form amyloid fibrils (reviewed in [37]). In summary, this work has demonstrated that sHsps can interact with monomeric, oligomeric, prefibrillar and fibrillar forms of target protein in order to prevent their aggregation, i.e. at each stage of the amyloid fibril-forming pathway. Based on this work we propose an expanded model of the chaperone action of sHsps (Fig. 2).

Most studies that have tested the in vitro chaperone action of sHsps have involved addition of the chaperone prior to aggregation commencing. Thus, the design of such studies does not address the effect(s) sHsps have on the latter stages of aggregation, which is as important to consider since, in vivo, levels of sHsps in the cell increase after aggregation has commenced as a result of the activation of the stress response [112,113]. Apart from interacting with monomeric species, sHsps also bind to species formed further along the aggregation pathway, including mature amyloid fibrils [114-117]. For example, when introduced during the elongation phase of $\alpha$ synuclein ( $\alpha$-syn) or amyloid- $\beta$ peptide $(\mathrm{A} \beta)$ aggregation, $\alpha \mathrm{Bc}$ prevents further fibril growth by binding along the length of mature fibrils, preventing secondary nucleation events that facilitate further fibril growth [114-116]. Our recent work, using apolipoprotein C-II (apoC-II) as a model fibril-forming protein, has shown that, by binding to fibrils, $\alpha \mathrm{Bc}$ stabilises them, preventing their (dilution-induced) fragmentation, and causes them to associate (tangle) into larger species reminiscent of protein inclusions [117]. Both fibril fragmentation and secondary nucleation can be the main sources of small oligomers thought to be responsible for the toxicity associated with the aggregation process [118]. Thus, the fibril-binding activity of sHsps helps to rationalise why sHsps (and indeed other Hsps) are found in protein deposits associated with disease, i.e. by binding to fibrils they facilitate their packing into inclusions, thereby limiting fibril fragmentation and secondary nucleation and providing an alternative protective mechanism to the cell. Recently $\alpha \mathrm{Bc}$ has also been shown to promote the dissociation of potentially toxic $\beta_{2}$-microglobulinoligomers into monomers, highlighting another role these chaperones may have in cells to protect them from the adverse effects of protein aggregation [119].

Despite our growing appreciation of the mechanisms by which sHsps interact with aggregating proteins there are still critical aspects of the chaperone model of sHsps that require further clarification: (1) There is no definitive 
evidence to-date that dissociated (dimeric) species are the sole chaperone active species (indeed for some sHsps such as $\alpha \mathrm{Bc}$ there is no direct evidence for the presence of dissociated species in solution) and some reports suggest that the large sHsp oligomers are also chaperone active [120,121]. For instance, some studies have indicated that there is no correlation between the concentration of sub-oligomeric species (or subunit exchange rate) and apparent chaperone activity [122]. Moreover, glutaraldehyde cross-linked $\alpha c$, which is incapable of subunit exchange, retains significant chaperone activity in vitro [121]. (2) Little is known about the stoichiometry of mammalian sHsp-target protein complexes. To-date, efforts to study, in precise detail, the manner by which sHsps bind to target proteins to form complexes have been hampered by the large, polydisperse and dynamic nature of sHsp oligomers and the low abundance of individual species in these heterogeneous samples. This problem is further confounded by the use of 'bulk' averaging techniques that can mask the presence of rare species formed in such dynamic systems. (3) The model is predominately based on in vitro studies of sHsp chaperone action; little is known about how this model relates to the chaperone activity of sHsps inside the crowded environment of the cell. For example, nothing is known about the precise concentrations of sHsps inside a cell (let alone cellular compartments such as the nucleus versus the cytoplasm) and since the oligomeric state of sHsps is concentration dependent (see discussion for Hsp27 below) it therefore remains to be elucidated which oligomeric forms are relevant in a cellular context.

Defining the precise molecular mechanisms that underpin the chaperone activity of sHsps is essential for understanding their role in the suppression of aggregation in cells. Such knowledge will in turn inform efforts aimed at exploiting the biological activity of sHsps in the treatment of diseases.

\section{SECTION II: Role of post-translational modification in the structure/function of sHsps}

sHsps undergo a variety of post-translational modifications. For example in the lens, $\alpha \mathrm{Ac}$ and $\alpha \mathrm{Bc}$ are subject to significant post-translational modification which includes phosphorylation, truncation (particularly within the unstructured C-terminal region), isomerisation, deamidation and glycation. In this section, we focus on phosphorylation as this post-translational modification occurs to sHsps in many tissues and, in the case of $\alpha$ Ac and $\alpha B c$, occurs early on in life, including before birth [123-125]. Moreover, phosphorylation of some sHsps occurs under conditions of cellular stress (see below), and is reversible (through the action of phosphatases) and is therefore thought to have an important functional role in dynamically altering the oligomeric distribution and chaperone ability of sHsps in response to stress. 
In contrast to phosphorylation, the other post-translational modifications are largely confined to the long-lived lens sHsps, $\alpha$ Ac and $\alpha \mathrm{Bc}$. Thus, they occur to a significant extent to these sHsps with age and are associated with aggregation of the crystallin proteins, and hence cataract formation. Within the lens, these modifications to the crystallins including $\alpha \mathrm{Ac}$ and $\alpha \mathrm{Bc}$, have been well summarised in a recent review [126]. Some salient points from experimental studies of $\alpha \mathrm{Ac}$ and $\alpha \mathrm{Bc}$ modifications are described below. All of these modifications have the potential to destabilise the structure of the proteins leading to crystallin unfolding and aggregation that ultimately contributes to cataract formation.

In vitro, it is well known that C-terminal truncation within the exposedC-terminal extension decreases the stability of both $\alpha \mathrm{Ac}$ and $\alpha \mathrm{Bc}$, particularly when most of the extension is removed [15]. Even greater truncation, i.e. further in from the C-terminal extension and into the C-terminal region, leads to significant structural changes. For example, Q151X $\alpha \mathrm{Bc}$, which contains the N-terminal region and the ACD but not the crucial I-X-I sequence, is a naturally occurring mutant that causes myopathy. Q151X $\alpha \mathrm{Bc}$ has little secondary structure and decreased oligomerisation and, in the presence of wild type $\alpha \mathrm{Bc}$, both proteins co-aggregate [127]. Intriguingly, Q151X $\alpha B c$ still exhibits chaperone activity. Isomerisation of L-aspartic acid to its $\mathrm{D}$-form is very prevalent in aged lens crystallins, including in $\alpha \mathrm{Ac}$ and $\alpha \mathrm{Bc}$ [126]. Of course, the introduction of a D-amino acid into any protein affects the local structure in the vicinity of the modification which, in the case of lens $\alpha \mathrm{Ac}$ and $\alpha \mathrm{Bc}$, leads to the disruption of the supramolecular crystallin order within the lens. Deamidation occurs extensively to $\alpha \mathrm{Ac}$ and to $\alpha \mathrm{Bc}$ with age in the human lens [128] and also to the $\beta$-crystallins (reviewed in [129]). Potentially, deamidation leads to destabilising structural changes due to the introduction of an additional negative charge from the resultant aspartic or glutamic acid sidechains [130]. Glycation is a common post-translational modification of lens $\alpha \mathrm{Ac}$ and $\alpha \mathrm{Bc}$ and is particularly associated with diabetes where increased levels of blood glucose are present [131,132]. Glycation leads to the formation of covalent cross-links, aggregation and compromised chaperone activity of $\alpha \mathrm{c}$ [8] with obvious implications for the development of diabetic cataract.

\section{Phosphorylation}

Both intra- and extra-lenticularly, the major post-translational sHsp modification is phosphorylation, the levels of which generally increase with age and under stress conditions [133-137]. For example, $\alpha \mathrm{Bc}$ is phosphorylated at 
three serine residues, Ser19, Ser45 and Ser59 [136,138,139]; phosphorylation at Ser45 is mediated by p44/p42 mitogen activated protein kinase (MAPK), at Ser59 by MAPK activated protein kinase 2 (MAPKAPK-2) $[136,140]$, whilst the kinase responsible for phosphorylation at Ser19 remains to be identified. Similarly, Hsp27 has three serine residues (Ser15, Ser78 and Ser82) that undergo phosphorylation [141,142]. MAPKAPK-2 is responsible for Hsp27 phosphorylation at all three sites [143,144]. In addition to $\alpha \mathrm{Ac}, \alpha \mathrm{Bc}$ and Hsp27, phosphorylation is also common to other sHsps such as Hsp20 $[145,146]$ and occurs readily in all tissues. Phosphorylation of Hsp20 occurs at Ser16 and is mediated by cyclic nucleotide-dependent protein kinases [147]. There have been other reports of sHsp serine phosphorylation (e.g. Hsp22 at Ser24 and Ser57 [148] and HSPB10 at Ser193 [149]), however the kinases responsible for these phosphorylation events in vivo remain to be definitively established.

The introduction of a strong negative charge via phosphorylation at serine residues in the $\mathrm{N}$-terminal region of $\alpha \mathrm{Bc}$ and Hsp27 alters their oligomerisation state. Phosphorylation reduces the average oligomer size, and increases oligomeric polydispersity and rate of subunit exchange of $\alpha \mathrm{Bc}[104,150-152]$, whereas it leads to a dramatic decrease in the size of Hsp27 oligomers, such that the triply phosphorylated isoform is predominately dimeric in solution [153,154]. Thus, under stress conditions, Hsp27 is phosphorylated, triggering dissociation of the large Hsp27 oligomers $[135,153,155,156]$ and an increase in the amount of exposed hydrophobicity on the newly formed Hsp27 dimers [157]. Phosphorylation also affects the cellular distribution of some sHsps. For example, following stress, phosphorylation of $\alpha \mathrm{Bc}$ and $\mathrm{Hsp} 27$ causes them to be translocated into the nucleus [158-162], presumably to protect nuclear proteins important to cell survival. Thus, phosphorylation of sHsps functions as a 'molecular switch' by regulating their structure and cellular localisation during periods of cellular stress.

While purified $\alpha \mathrm{Bc}$ from bovine lens has been used to investigate of the effects of phosphorylation on $\alpha \mathrm{Bc}$ structure and function (as it is extensively phosphorylated with age $[123,125,138,139,163])$, such sources of sHsps do not afford homogeneous phosphorylated isoform. Instead these contain a mixture of non-phosphorylated, mono-, di- and/or tri-phosphorylated forms in the one oligomer. Denaturation and subsequent ion-exchange high performance liquid chromatography can be used to separate these phosphorylated forms [164,165], however denaturation modifies the oligomeric state and activity of $\alpha \mathrm{Bc}$ once it is refolded [166]. As an alternative, phosphomimics are useful tools to investigate the effects of phosphorylation upon sHsp structure and function. 
Phosphomimics are created by replacing phosphorylatable serine residues with a negatively charged amino acid, such as aspartic acid or glutamic acid, to mimic the negative charge introduced by the addition of the phosphate group. The main advantage of phosphomimics is that they afford a single homogeneous isoform of the protein. Significantly, phosphomimics of $\alpha \mathrm{Bc}$ and Hsp27 have similar attributes to the phosphorylated forms of the protein with regards to their oligomeric distribution, chaperone activity, subcellular localisation and cellular trafficking $[154,161,167,168]$. For example, the translocation of $\alpha \mathrm{Bc}$ to the nucleus and its association with nuclear speckles during mitosis is phosphorylation-dependent and this is replicated by the $\mathrm{S} 19 \mathrm{D} / \mathrm{S} 45 \mathrm{D} / \mathrm{S} 59 \mathrm{D} \alpha \mathrm{Bc}$ phosphomimic [161] and both in vitro phosphorylated Hsp27 and the S15D/S78D/S82D Hsp27 phosphomimic have comparable abilities to prevent the aggregation of target proteins in vitro [154]. Both S59 phosphorylated and S59E phosphomimicking forms of $\alpha \mathrm{Bc}$ bind to the anti-apoptotic regulator Bcl-2, promoting apoptosis of breast cancer MCF7 cells and therefore making them more susceptible to chemotherapeutic agents [169].

The precise effect that phosphorylation has on the chaperone function of sHsps remains controversial. For example, some studies have concluded that Hsp27 phosphorylation increases chaperone activity (for example, $[154,156])$, others have reported no difference [170] whilst others have found that phosphorylation decreases activity [153]. Similar discrepancies exist in the literature with regards to the effect of phosphorylation on $\alpha B c$ 's chaperone activity $[151,152,165,167]$. Various factors may account for these apparent differences including the target protein used to assess the chaperone activity, the final concentration of sHspin the assays (wild-type Hsp27 dissociates at low concentrations and therefore may be predominately dimeric, like the phosphorylated form, in some assays $[154,156])$, and buffer and temperature conditions of the assay, all of which influence sHspchaperone activity [151]. Overall, the consensus emerging from work with $\alpha \mathrm{Bc}$ and Hsp27 concerning the impact of phosphorylation on sHsp chaperone function is that phosphorylation boosts chaperone activity and does so by (i) promoting dissociation of large oligomers into smaller species $[104,150,151,153,154]$ and (ii) enhancing their affinity to bind destabilised target proteins $[111,156]$. Based on structural modelling of a full-length $\alpha \mathrm{Bc}$ into a 24-mer oligomer [171], recent work has concluded that the negative charges introduced into the N-terminal domain of $\alpha \mathrm{Bc}$ by phosphorylation at S19, S45 and S59 result in oligomer destabilisation and dissociation due to the close proximity of adjacent $\mathrm{N}$-terminal domains in the higher-order oligomeric structure [104]. Moreover, phosphorylation increases the rate of subunit exchange between oligomers and the flexibility of the $\mathrm{N}$-terminal domain, leading to an increase in chaperone activity [104]. 
With regards to the overall impact of sHsp phosphorylation in a cellular context, it is envisaged that under normal conditions sHsps exists at relatively low levels in most cells and in non-phosphorylated forms (Figure 3). The activity of sHsps under these conditions is sufficient to maintain cellular proteostasis. Upon stress, the sHsps are rapidly phosphorylated, which modifies their oligomeric state and facilitates their translocation into the nucleus where they interact with and bind to destabilised proteins in danger of aggregating and precipitating. Prolonged or chronic cell stress (e.g. that which occurs during some diseases) leads to an increase in sHsp levels in the cell (due to their up-regulation as part of the heat-shock response pathway). This increase in expression facilitates the formation of a heterogeneous pool of sHsp oligomers (including phosphorylated and non-phosphorylated forms), which maximises the possible binding interactions of the sHsps with various intracellular target proteins.

\section{SECTION III: sHsps and their roles in disease}

In extra-lenticular tissues, the roles played by sHsps may vary according to specific cell and tissue types. Further complicating the picture in vivo is that the entire range of interactions of sHsps with target proteins that may occur in the crowded environment of the cell are not easily replicated by in vitro experiments [6]. Just as the precise mechanism(s) of action of sHsps in protein stabilisation remain to be elucidated in vivo, the precise roles of sHsps in the cellular pathologies of many diseases also remain largely unclear. As a result of their increased expression under a variety of cellular stresses, particularly those present in pathological states (i.e. heat /inflammation, oxidation, ischaemia), it is perhaps not surprising that sHsps and their (mal)function have been associated with a plethora of diseases including neurodegenerative diseases, multiple sclerosis and cancers [4-6,172-174].

Elucidating the precise role(s) played by sHsps in the context of disease is complex as they may be present as a consequence or cause of the disease. Moreover, as a result of their ubiquitous role in interacting with and stabilising a wide range of partially unfolded proteins against aggregation, sHsps are involved in many processes central to disease development and manifestation. These include cellular growth and differentiation $[90,175,176]$; interaction with cytoskeletal components such as actin and intermediate filaments [6,177,178]; and apoptosis [179]. Several of the sHsp family members (Hsp27, $\alpha \mathrm{Bc}, \mathrm{Hsp} 20$ and HSPB2) have been attributed a protective role in the development of neurodegenerative and neuromuscular diseases, roles thought to be related to their abilities to both stabilise target proteins and to interact with cytoskeletal elements as the key features of these diseases are protein aggregation and defective axonal transport [6].

\section{The role of sHsps in neurodegenerative disease}


$\alpha \mathrm{Bc}$ is expressed at high levels in the neurons and glial cells of patients with neurodegenerative diseases such as Alzheimer's (AD), Huntington's, Alexander, Neuman-Pick, Creutzfeldt-Jakob (CJD) and amylotrophic lateral sclerosis (ALS) (summarised in [6]). Furthermore, $\alpha \mathrm{Bc}$ inhibits the in vitro aggregation of glial acidic fibrillary protein (GAFP) and $\alpha$-syn which are associated with Alexander and Parkinson's disease (PD) pathologies, respectively [180,181]. Hsp20 and Hsp22 are also present at increased levels following neuronal stress associated with $\mathrm{AD}$, PD, and ALS [4,182-185]. Hsp27 is also upregulated in AD and Neuman-Pick diseases [6]. $\alpha \mathrm{Bc}$ and/or Hsp27 have also been identified in the protein deposits characteristic of several neurodegenerative and neuromuscular diseases (see below), co-depositing with the protein or peptide identified as being responsible for the pathological features of the disease [84].

The Rosenthal fibres characteristic of Alexander disease constitute abnormal inclusions containing $\alpha \mathrm{Bc}$ (some of which is ubiquitinated) [186], Hsp27 and GAFP $[187,188]$. The involvement of Hsp27 and $\alpha \mathrm{Bc}$ in the formation of Rosenthal fibres within astrocytes is believed to be a response to an as-yet unknown stress caused by the disease [83]. The close association of sHsps with intermediate filaments in these pathologies [187] indicates that sHsps may play a role in their structural rearrangement [189]. Rosenthal fibres accumulate as a result of insufficient protein degradation in the cell. $\alpha \mathrm{Bc}$ 's lysine residues, particularly the three in the solvent-exposed and highly flexible C-terminal extension (K166, K175 and K174) [16] serve as potential sites for the binding of ubiquitin in order to target the protein for degradation [190-192]. The presence of $\alpha \mathrm{Bc}$-ubiquitin conjugates in such pathological inclusions implies a breakdown of the cell's protein degradation system.

The pathology of $\mathrm{AD}$ is characterised by extracellular accumulation of amyloid plaques and intracellular neurofibrillary tangles [193]. Amyloid plaques are composed primarily of $A \beta$ peptides which are derived from the abnormal processing of $\alpha$-amyloid precursor protein by $\beta$-secretase. In patients with familial $A D$, overproduction of $\mathrm{A} \beta$ leads to early onset $\mathrm{AD}$ [194-197]. The level of $\alpha \mathrm{Bc}$ expression in brains of patients suffering $\mathrm{AD}$ is markedly increased compared to that in the normal human brain $[113,198]$ presumably due to the cellular stress caused by disease. We and others have shown that aggregation of $\mathrm{A} \beta$ and its associated cellular toxicity is prevented by $\alpha \mathrm{Bc}$ [199] or its isolated ACD [26] and thus sHsp overexpression in the context of $\mathrm{AD}$ may be as a protective mechanism. Fändrich et al. have shown that there is an intracellular component to the aggregation and pathogenic nature of $\mathrm{A} \beta$ which may explain the presence of $\alpha \mathrm{Bc}$ in the extracellular plaques of $\mathrm{AD}$ [200]. The intracellular neurofibrillary tangles characteristic of AD (and other 'tauopathies') contains 
hyperphosphorylated tau protein [201]. Both $\alpha \mathrm{Bc}$ and $\mathrm{Hsp} 27$ are also found in these tangles, however, their contributions to the formation of these plaques and tangles, and hence the pathology of $\mathrm{AD}$, remains unclear [202].

The presence of $\alpha \mathrm{Bc}$, Hsp27 and ubiquitin in CJD is thought to be related to the degenerative processes that neurons undergo as the disease manifests [191]. CJD is a transmissible spongiformencephalopathy resulting from the intracellular deposition of misfolded prion protein $\left(\operatorname{PrPsc}^{\mathrm{sc}}\right)$. The bovine precursor of this misfolded protein associates with $\alpha \mathrm{Bc}$ both in vitro and in vivo [203]. However, it remains unclear as to whether $\alpha \mathrm{Bc}$ acts to inhibit or enable the conversion of correctly folded prion to its toxic PrPsc form. Ubiquitinated $\alpha \mathrm{Bc}$ has also been identified by immunochemical analysis in cytoplasmic inclusions in brains of patients with multiple system atrophy [204]. More recently, it has been shown that the aggregation of SOD1, a major protein involved in the pathogenesis of ALS, is prevented by both $\alpha \mathrm{Bc}$ and Hsp27 [205,206] and that Hsp22, in concert with other chaperones, promotes autophagic removal of misfolded proteins in ALS [184].

PD is characterised by a gradual loss of dopaminergic neurons in the brain. The precise role of $\alpha \mathrm{Bc}$ (and other sHsps) in the development and progression of this disease is still unknown [207], despite the findings that the disease is characterised by 'ballooned' neurons [208] which express $\alpha \mathrm{Bc}$ [113]. Both PD and Huntington's disease are intracellular protein aggregation diseases, like CJD. We have previously demonstrated that $\alpha \mathrm{Bc}$ prevents the aggregation of $\alpha$-syn, the principal protein in Lewy body deposits, and that $\alpha \mathrm{Bc}$ also binds to intact $\alpha$-syn fibrils to prevent their further growth $[114,115,180]$. Furthermore, several sHsps (Hsp20, Hsp22, HspB7 and HspB9) inhibit the aggregation of the polyQ huntingtin protein responsible for Huntington disease and also protect against cell death triggered by the deposition of the aberrant protein [4,209]. Our subsequent studies have shown, however, that polyQ aggregation occurs in stages, and while $\alpha \mathrm{Bc}$ potently inhibits the first stage of fibril formation by the polyQ protein, ataxin (responsible for spinocerebellar ataxia), through interaction with its Josephin (flanking) domain, the second stage of polyQ aggregation can still proceed [210]. The potency of sHsps in individual disease states therefore appears to be very much dependent on target protein aggregation models and specific sequences can modulate this effect.

\section{The role of sHsps in mul tiple sclerosis}

Multiple Sclerosis (MS) is a relatively common demyelinating neurodegenerative disease. The exact mechanism of demyelination is unknown but appears to be an autoimmune disorder, triggered by environmental factors (e.g. 
viral infection). Patients with MS have numerous demyelinated plaques in the brain and spinal cord and these lesions have varying histopathological profiles depending on the stage of disease (i.e. acute or chronic). Inflammation plays a central role in disease progression as macrophages initially phagocytose the degraded myelin to form an acute plaque (with other immune cells such as T-lymphocytes and plasma cells) before a reactive gliosis is established, leading to chronic inflammation and plaque formation. It has been shown that $\alpha \mathrm{Bc}$ is the most prominent protein present in plaques of MS patients [211] and the CRYAB gene is the most highly induced in plaque tissue compared to normal tissue [212]. The increased expression of $\alpha \mathrm{Bc}$, along with other Hsps, is proposed to be part of the oligodendrocyte's survival response [192]. Initial studies identifying $\alpha B c$ bound to antibodies in the sera of affected patients suggested $\alpha \mathrm{Bc}$ as an auto-antigen to human T-cells in MS [4,213,214]. Subsequent studies showed that most of the sHsps (HspB1-8) were capable of binding immunoglobulin molecules with varying affinities and through multiple binding sites [214]. The association of these proteins with antibodies in the context of MS therefore appears to be related to their intrinsic ability to bind immunoglobulins rather than any inherent immunogenic property of the sHsp itself. As proposed by Clark and Muchowski [172], the upregulation of sHsps in diseases characterised by hyper- or autoimmune responses such as MS may lead to stabilisation of antigenic components by the chaperones which then act to exacerbate an immune response.

\section{The role of sHsps in cancer}

Several sHsps, particularly Hsp27 and $\alpha \mathrm{Bc}$, have been identified as playing potential roles in the pathogenesis of cancer. Both $\alpha \mathrm{Ac}$ and $\alpha \mathrm{Bc}$ have been found in a range of tumours [84] and especially in high-grade tumours [215]. Hsp27 has been identified at high levels in metastatic tissues compared to non-metastatic tissues, indicating a role in the metastasis of cancer [216,217]. Indeed, the ability to regulate apoptosis and thus prolong cell life, which in some cases is tumorigenic, is a feature consistent with the finding that Hsp27 and $\alpha \mathrm{Bc}$ expression is associated with increased cellular resistance to cytostatic agents [218]. Interestingly, the metastatic properties of breast cancer cells can be inhibited by phosphorylation of $\alpha \mathrm{Bc}$. Phosphorylation at S59 specifically reduces the anti-apoptotic action of the protein, by affecting oligomer formation [217,219].

In terms of the mechanisms by which sHsps promote tumorigenesis, many pathways have been identified by which sHsps regulate both the intrinsic and extrinsic pathways of apoptosis. For example, Chen et al. showed 
that both $\alpha \mathrm{Ac}$ and $\alpha \mathrm{Bc}$ are able to bind to the pro-apoptotic $\mathrm{Bcl}-2$ proteins $\mathrm{Bax}$ and $\mathrm{Bcl}-\mathrm{X}_{\mathrm{s}}$, inhibiting their mitochondrial translocation and thereby switching off the intrinsic cell death pathway [215]. Specific naturallyoccurring mutations in the $\alpha$-crystallins (R116C $\alpha \mathrm{Ac}$ and $\mathrm{R} 120 \mathrm{G} \alpha \mathrm{Bc}$ ) impair the ability of these sHsps to sequester Bax and Bcl-X $\mathrm{X}_{\mathrm{S}}$ [220]. Previous work has also shown that Hsp27 interacts directly with Daxx to prevent Fas-mediated apoptosis [221], a cell death pathway that involves Hsp27 [222]. Future therapies may therefore include those which aim to suppress the action of sHsps in such situations [84]. For example, a recent clinical trial of an antisense oligonucleotide (ASO; OGX-427) designed to specifically inhibit the expression of Hsp27 for the treatment of prostate, bladder, breast and lung cancer has shown promising results [79].

\section{The role of sHsps in cataract and myopathies}

Several naturally-occurring mutations in sHsps have been identified as being responsible for various forms of human cataract and myopathy. These will be discussed further in the following section describing the occurrence and phenotypic effects of specific mutations in sHsps.

\section{SECTION IV: Naturally-occurring mutations in sHsps - implications for al tered function and disease}

Our understanding of the roles played by sHsps in disease aetiology has been increasingly enhanced by the identification of sHsp mutations directly associated with specific pathologies (Table 2). Typically, these mutations lead to altered chaperone function and therefore provide a clear link between molecular chaperone action and disease manifestation.

\section{Mutations in the $\alpha$-crystallin domain}

A naturally-occurring missense mutation (R120G) in the conserved ACD of $\alpha \mathrm{Bc}$ was first identified as being responsible for a form of desmin-related myopathy (DRM) [223]. R120G $\alpha \mathrm{Bc}$ is associated with aggregation of the intermediate filament protein, desmin, in the cytoplasm of myocytes [224]. Desmin is essential for tensile strength in myofibrils of striated muscle and as a result DRM manifests with progressive muscle weakness. Moreover, gene mutations producing DRM are clinically heterogeneous with affected individuals often also exhibiting cardiomyopathy and cataract $[223,225]$. The formation of desmin aggregates was initially attributed to loss of chaperone function in $\alpha \mathrm{Bc}$ as a result of the $\mathrm{R} 120 \mathrm{G}$ mutation, a hypothesis supported by the finding that 
formation of desmin aggregates could be delayed or prevented in vivo by the addition of wild-type $\alpha \mathrm{Bc}$ or other molecular chaperones [226]. Subsequent studies by our group and others have shown that the R120G mutation causes significant structural changes in $\alpha \mathrm{Bc}$ compared to the wild-type protein, leading to a loss of chaperone activity in vitro [227] and an inherent instability in the mutated protein [228]. Similarly, D140N $\alpha$ Bc, a mutant identified in relation to congenital lamellar cataract, exhibits abnormal oligomerisation and impaired chaperone activity [229,230]. Recent biophysical studies by Hilton et al. [12] support the rationale that mutations in the ACD of $\alpha \mathrm{Bc}$ interfere with important transient interactions between subunits and therefore impact on the association and dissociation properties of the oligomeric form. The locations of naturally-occurring, disease-associated mutations in a model of the $\alpha \mathrm{Bc}$ monomer are shown in Fig. 4 .

Mutation in $\alpha \mathrm{Ac}$ at the equivalent residue to $\mathrm{R} 120 \mathrm{G}$ in $\alpha \mathrm{Bc}$ (i.e. R116C) results in hereditary cataract [231] and similar mutations in the gene coding for $\alpha$ Ac have profound effects on lens opacity [232]. Mutation of R116 in the $\mathrm{ACD}$ of $\alpha \mathrm{Ac}$ causes a decrease in chaperone activity and subsequent aggregation of the natural target proteins of $\alpha \mathrm{Ac}$ in the lens (the $\beta$ - and $\gamma$-crystallins) [172]. Alteredchaperone activity in R116C $\alpha \mathrm{Ac}$ (as with R120G $\alpha \mathrm{Bc}$ ) results from secondary and tertiary structural changes and increased oligomeric size as a result of the mutation [233-235]. The substitution of an arginine for a cysteine at this position exposes a previously buried residue which most likely disrupts salt bridges and potentially leads to the formation of non-native, inter-subunit disulphide bonds [236]. It is highly likely therefore that perturbation at this site is the reason for the abnormal oligomeric assembly of $\mathrm{R} 116 \mathrm{C} \alpha \mathrm{Ac}$. This same residue is affected in the $\mathrm{R} 116 \mathrm{H}$ mutant of $\alpha \mathrm{Ac}$ which also causes cataract [237]. As discussed in Section I, the interaction between $\alpha \mathrm{A}-$ and $\alpha \mathrm{Bc}$ is crucial to the maintenance of lens transparency. The $\mathrm{R} 116 \mathrm{C}$ mutation in $\alpha \mathrm{Ac}$ also leads to a reduction in its protective ability against epithelial cell apoptosis in the lens [238]. A number of other site-specific mutations involving residues within the ACD have been found to be responsible for the development of either whole (lenticular) or nuclear cataract in humans (R49C and G98R $\alpha \mathrm{Ac}$ ) [239], or in mice (R54C/Y118D $\alpha \mathrm{Ac})$ [240].

Six naturally-occurring mutations in Hsp27 have been identified that are associated with Charcot-Marie-Tooth (CMT) disease, an inherited motor and sensory neuropathy, and distal hereditary motor neuropathy (HMN). Three of these mutations, R127W, S135F (one causing CMT and the other HMN) and R136W, are located in the ACD [241]. Neuronal cells transfected with the mutant Hsp27s are less viable than those expressing wild-type Hsp27 
and mutation also leads to altered neurofilament assembly within cells [241]. Similar mutations in the ACD of Hsp22, (i.e. K141E [242], K141T [243] and K141N [242,244,245]), also give rise to CMT disease, indicating a critical role for sHsps in both motor and sensory neurons. R140G [246] and K141Q [247] mutations in Hsp27 cause distal HMN.

\section{Mutations in the C-terminal region}

Outside of the ACD, naturally-occurring mutations in the $\mathrm{C}$-terminal regions of both $\alpha \mathrm{Ac}$ and $\alpha \mathrm{Bc}$ are associated with disease. Mutation of conserved residues in $\alpha \mathrm{Bc}, \mathrm{R} 157 \mathrm{H}$ and $\mathrm{G} 154 \mathrm{~S}$, lead to dilated cardiomyopathies but not cataract [248,249]. As discussed above, another form of DRM arises from a deletion mutation (Q151X) in $\alpha \mathrm{Bc}$ [250]. Similarly, several other naturally-occurring mutations in the C-terminal region of Hsp27, T151I [241], T180I [251], P182L [241] and P182S [252] cause HMN. Other rarer forms of fibrillar neuropathy have been identified, with deletions in the gene encoding $\alpha \mathrm{Bc}(\mathrm{CRYAB})$ resulting in the absence of the proteinfrom affected muscle fibres [253]. A naturally-occurring deletion of a single nucleotide base in the CRYAB gene has been described and leads to a frameshift mutation in the C-terminal region of the resulting $\alpha \mathrm{Bc}$ protein [229]. Replacement of the wild-type sequence after residue 149 with 35 novel residues (450delA) results in posterior polar cataract [229]. Similarly, deletion of two bases in CRYAB leads to truncation at position 464 (del464CT), giving a myofibrillar myopathy phenotype [250]. These provide further evidence for the importance of the Cterminal region in the function of sHsps. The complex phenotypical profiles associated with naturally-occurring mutations of $\alpha \mathrm{Bc}$ and Hsp27 are a consequence of their widespread tissue distributions (which largely overlap) and their wide array of cellular functions.

\section{Mutations in the $\mathbf{N}$-terminal region}

In the N-terminal region, there are small regions of high $(\geq 85 \%)$ sequence identity between members of the sHsp family. Thus, residues 48-55 in $\alpha \mathrm{Bc}$ encompass the RLFDQxFG motif, which is also present in Hsp27 and Hsp20 [254]. Several naturally-occurring mutations in the N-terminal region of Hsp27 have been shown to exist in individuals affected by distal HMN (Table 2; [246]).

The P20S mutant of $\alpha \mathrm{Bc}$ is the only cataract-causing mutation to be identified outside the ACD, but it affects a highly conserved N-terminal residue that also impairs the chaperone activity of $\alpha$ Ac [255]. The naturallyoccurring mutation W9X in $\alpha$ Ac has also been identified in individuals with cataract [256,257], as have mutations 
involving R21 (Table 1; [258-260]). Similarly, R49C [256] and R54H $\alpha$ Ac [240] cause cataract, with R49C $\alpha$ Ac exhibiting impaired chaperone function in vivo, resulting in greater perturbation of oligomer distribution and higher levels of cell death than even R116C $\alpha$ Ac [256]. Furthermore, the same mutation induces apoptosis in human lens epithelial cells, an effect thought to be related to aberrant phosphorylation at S19, S45 and S59 of $\alpha \mathrm{Bc}$, leading to its nuclear import and accumulation which results in subsequent cell death [255]. 


\section{Future perspectives}

From the above, it is apparent that there is still a great deal to learn about sHsps - they are an enigmatic class of molecular chaperone proteins. They appear to have many roles in cells, all of which are based around their ability to stabilise other proteins, thereby preventing their misfolding and potential aggregation under both normal (constitutive) and abnormal (stress) conditions in the cell. Their ability to interact with amyloid fibril-forming proteins at the various stages of their aggregation pathway also imparts a multi-functional dimension to sHsp chaperone activity.

To rationalise sHsp functions will require a continued concerted effort on various fronts to:

1. Understand fully the mechanism and role of sHsp subunit exchange (if any) in chaperone action.

2. Understand the functional role of each of the three sHsp structural regions.

3. Determine an accurate quaternary structure for $\alpha \mathrm{B}$-crystallin and other sHsps (which, most likely, will provide major insight into points 1 and 2).

4. Understand, and explain, the role of post-translational modification, particularly phosphorylation, in sHsp chaperone action.

5. Understand why nature provided so many distinct sHsps - a feature indicating a need for diversity and/or compartmentalisation of sHsp functionalities.

With the rapid advances in the last five years of biophysical and spectroscopic techniques that can be used to study large and dynamic protein complexes (e.g. mass spectrometry, X-ray crystallography, solution and solid state NMR, electron microscopy, SAXS and SANS), there is vastly increased scope for examining the structure and mode of action of the previously elusive dynamic and polydisperse mammalian sHsps. As a result, many of these powerful techniques, previously applied in isolation, are being used in combination with significant success to build up a more complete picture of sHsp structure, dynamics and mechanism of chaperone action [27-29]. Furthermore, with the advent of single-molecule fluorescence techniques, whereby individual protein molecules can be studied in isolation, avoiding the bulk averaging that can mask rare or short-lived species, the next decade holds much promise with regards to unravelling the precise structure-function relationship of sHsps. The culmination of this work will be the development of molecules that can regulate the activity of sHsps in the context of providing therapies for treatment of the wide range of diseases associated with protein misfolding and 
aggregation, many of which (e.g. $\mathrm{AD}, \mathrm{PD}$ and cataract) are becoming increasingly prevalent amongst our ageing population.

\section{Acknowledgements}

The authors sincerely thank Dr. Andrew Aquilina and Prof. Roger Truscott for valuable discussions and assistance with the preparation of this manuscript and Prof. John Clark and Dr Joy Ghosh for the co-ordinates of the $\alpha \mathrm{B}$ crystallin monomer. We also thank Prof. Justin Benesch for providing the X-ray crystal structure of the ACD and C-terminal region of $\alpha \mathrm{B}$-crystallin and we are grateful to the anonymous reviewers for their helpful comments and suggestions. SM was supported by a Royal Society Dorothy Hodgkin Fellowship, HE is supported by an Australian Research Council Future Fellowship (FT110100586) and JC is supported by a National Health and Medical Research Council Project Grant (\#1068087). 


\section{Tables}

Table 1 Tissue distribution of the major sHsps

\begin{tabular}{|c|c|c|}
\hline sHsp & Alternative name & Tissue distribution \\
\hline$\alpha \mathrm{Ac}$ & HSPB4 & Eye lens, spleen, thymus [261] \\
\hline$\alpha \mathbf{B c}$ & HSPB5 & $\begin{array}{l}\text { Eye lens, retina, heart, skeletal muscle, skin, brain, spinal cord, kidneys, lungs } \\
{[44,64,65] \text {, cochlea [66], lacrimal gland duct \& tears [68], sciatic nerve [6] }}\end{array}$ \\
\hline Hsp27 & HSPB1 & $\begin{array}{l}\text { Skeletal, cardiac and smooth muscle, brain and spinal cord (summarised in } \\
\text { [6]) }\end{array}$ \\
\hline Hsp22 & HSPB8 & Muscle, brain, spinal cord (summarised in [6]) \\
\hline Hsp20 & HSPB6 & $\begin{array}{l}\text { Skeletal, cardiac and smooth muscle, brain, spinal cord, sciatic nerve } \\
\text { (summarised in [6]) }\end{array}$ \\
\hline
\end{tabular}


Table 2 Disease-causing sHsp mutations in humans

\begin{tabular}{|c|c|c|}
\hline sHsp & Mutant & Disease \\
\hline$\alpha$ Ac & $\begin{array}{l}\text { W9X, R12C, R12W, R21L, R49C, } \\
\text { R54H, G98R, R116C*, R116H* }\end{array}$ & Cataract $[231,237,239,240,256,258-260,262]$ \\
\hline$\alpha B c$ & R120G* & Desmin-related myopathy, cataract [223] \\
\hline$\alpha \mathbf{B c}$ & P20S, R56W, D140N, 450delA & Cataract $[229,230,255,263]$ \\
\hline$\alpha \mathbf{B c}$ & R157H, G154S & Dilated cardiomyopathy [248,249] \\
\hline$\alpha \mathbf{B c}$ & Q151X (STOP) & Desmin-related myopathy $[127,250]$ \\
\hline$\alpha \mathbf{B c}$ & 454delCT CRYAB gene & Desmin-related myopathy [250] \\
\hline$\alpha \mathbf{B c}$ & 450delA CRYAB gene & Cataract [229] \\
\hline Hsp27 & $\begin{array}{l}\text { R127W, S135F, R136W, T151I, } \\
\text { P182L }\end{array}$ & $\begin{array}{l}\text { Distal hereditary motor neuropathy, motor and sensory } \\
\text { neuropathy, Charcot-Marie-Tooth disease [241] }\end{array}$ \\
\hline Hsp27 & P182S & Distal hereditary motor neuropathy [252] \\
\hline Hsp22 & K141N*, K141E*, K141Q & Distal hereditary motor neuropathy $[242,244]$ \\
\hline Hsp27 & T180I & Distal hereditary motor neuropathy [251] \\
\hline Hsp22 & $\mathrm{K} 141 \mathrm{~N}^{*}$ & Charcot-Marie-Tooth disease [245] \\
\hline Hsp22 & K141T* & Charcot-Marie-Tooth disease [243] \\
\hline
\end{tabular}

*Residue 116, 120 and 141 in $\alpha \mathrm{A}-, \alpha \mathrm{Bc}$ and Hsp22, respectively, are equivalent. 
Figures

Primary sequence of aB

Fig. 1A

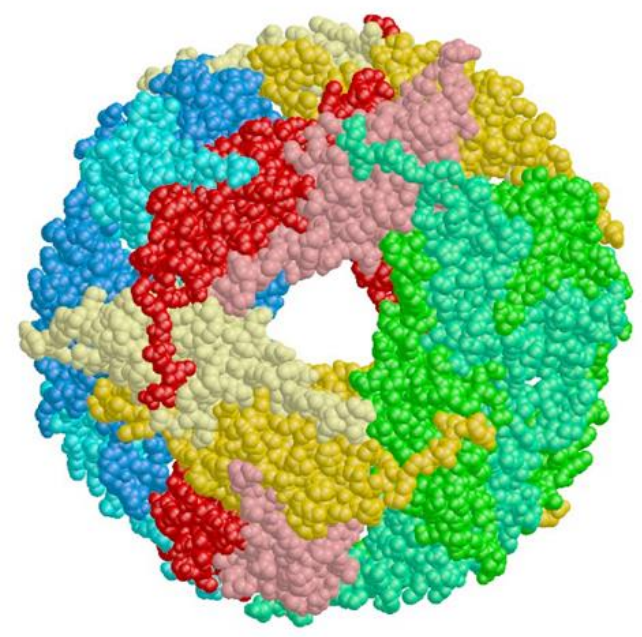

Fig. 1B

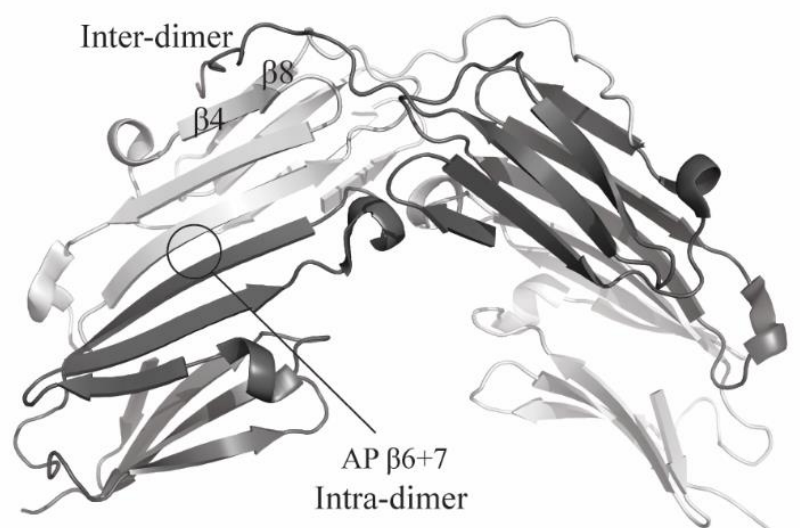

Fig. 1C 


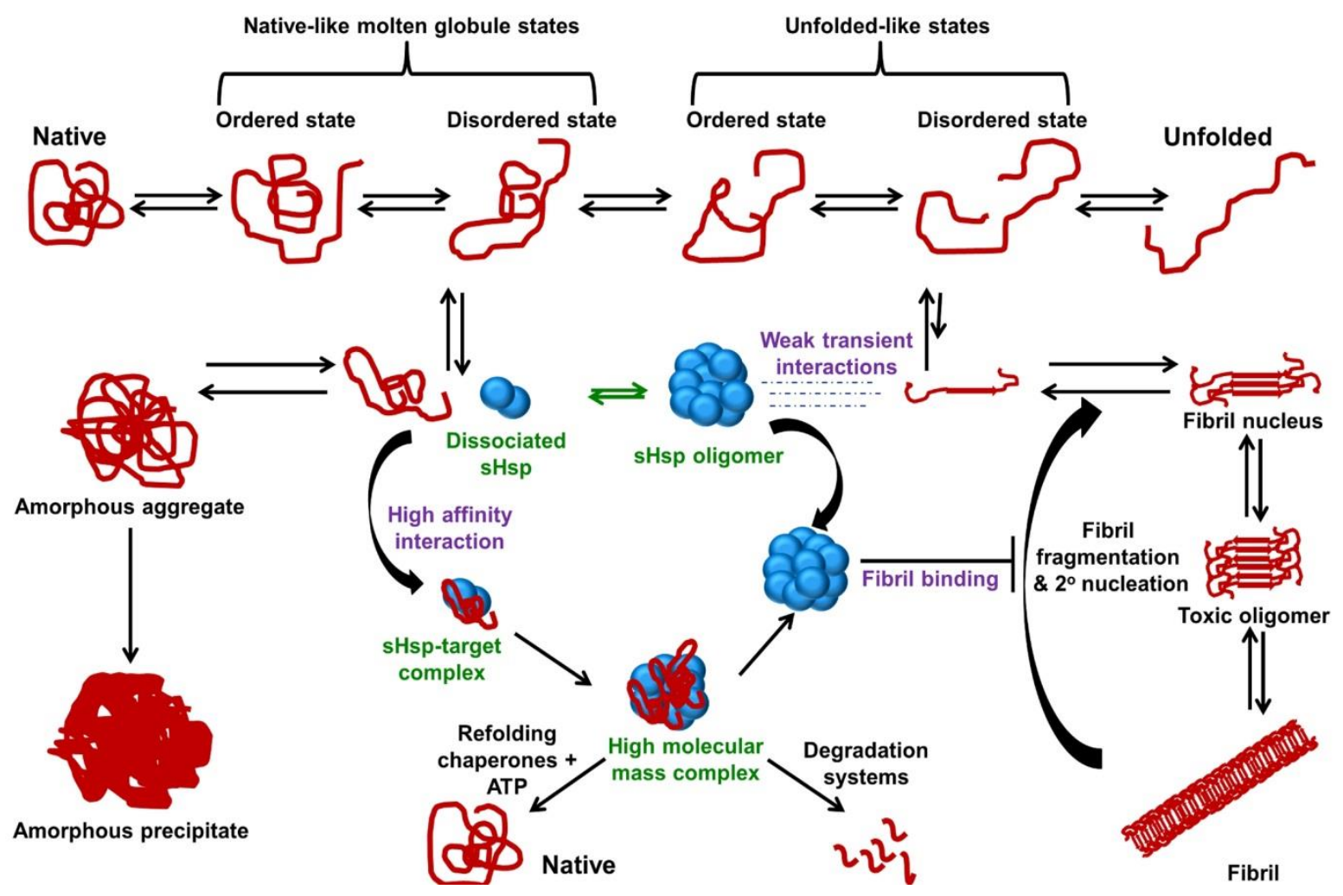

Fig. 2

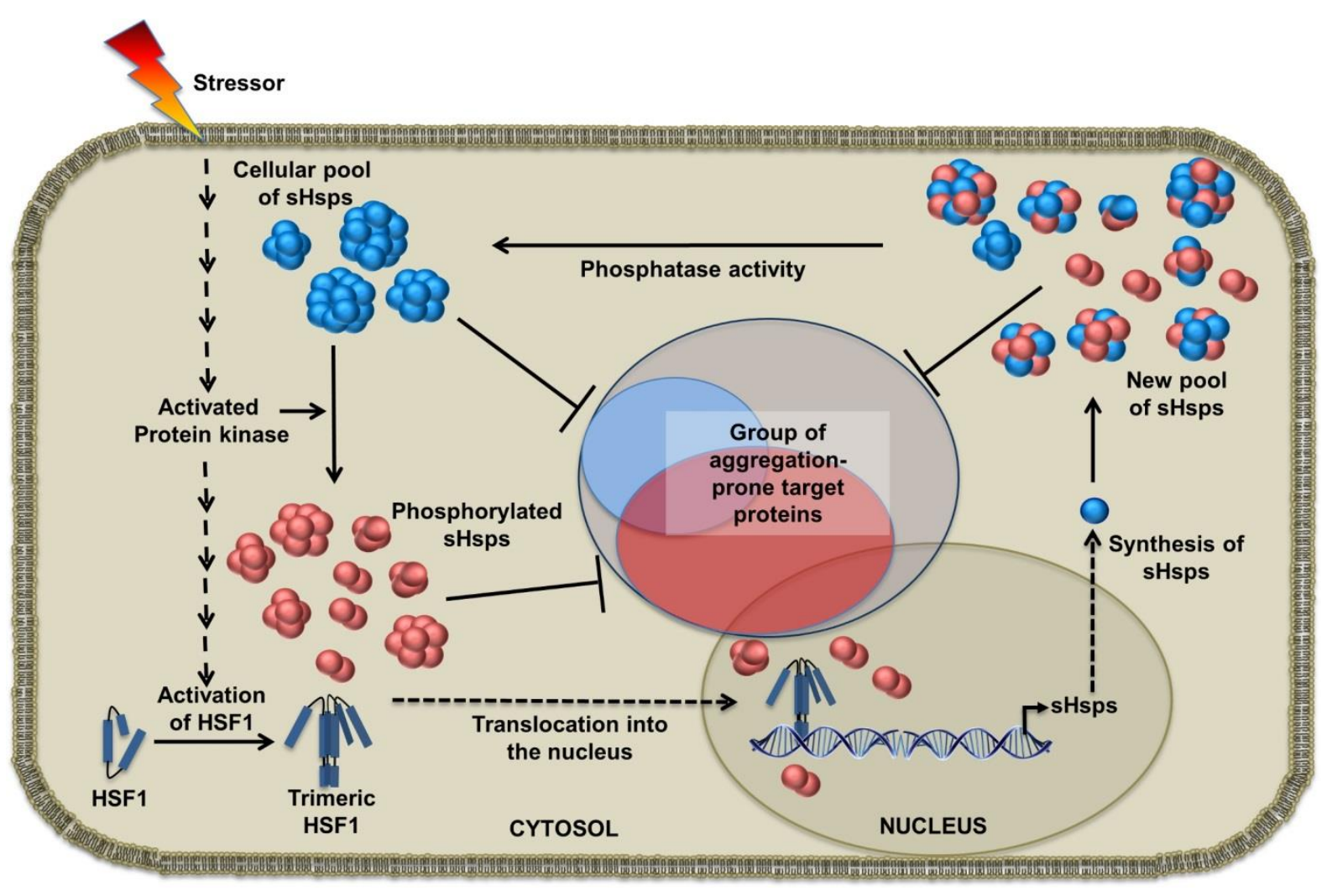

Fig. 3 


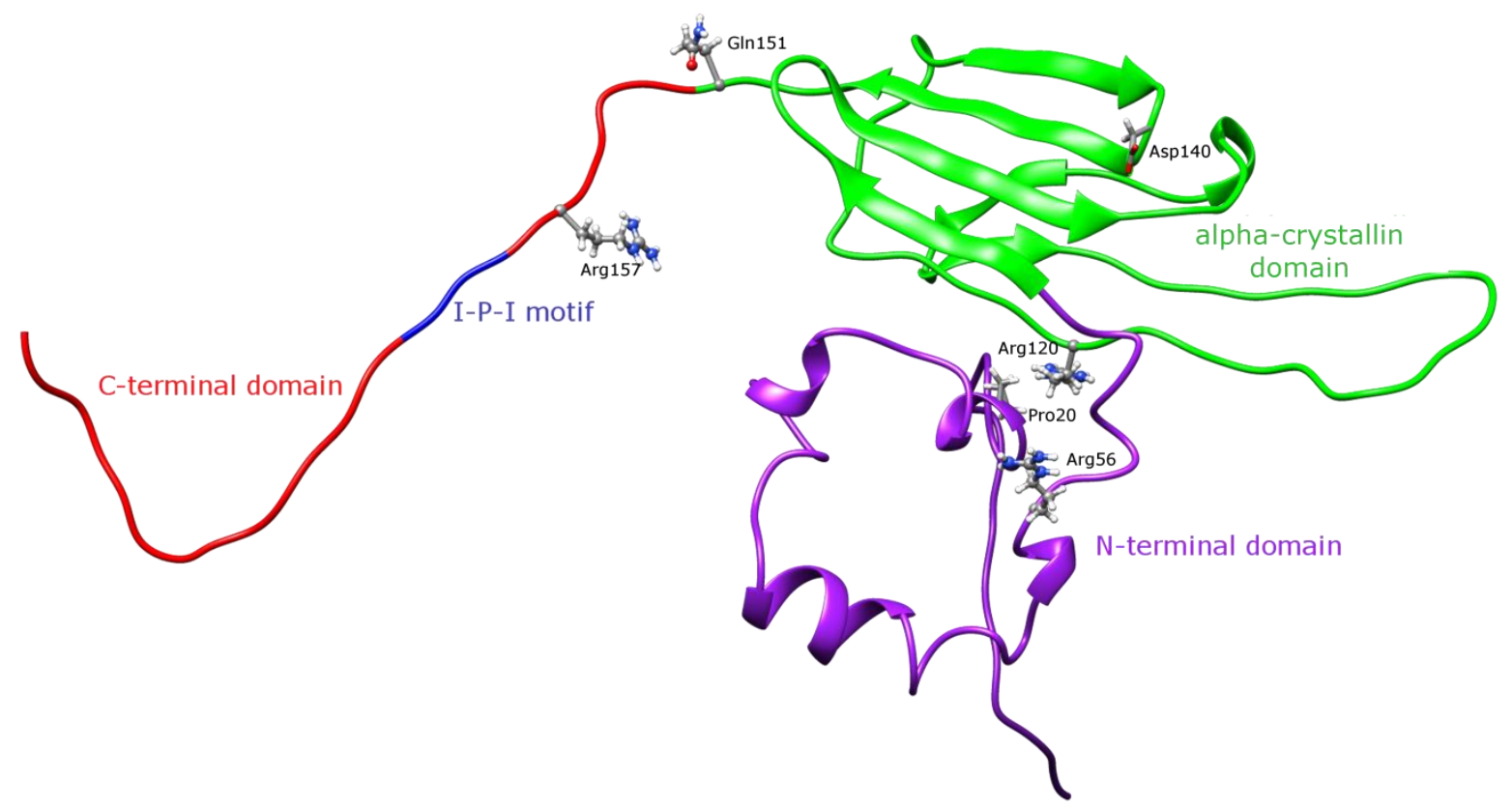

Fig. 4 


\section{Figure Legends}

Fig. 1A Schematic arrangement of the various structural regions in human $\alpha \mathrm{Bc}$. The $\beta$-sheet-rich ACD is flanked by the relatively unstructured $\mathrm{N}$ - and C-terminal regions. The latter contains the highly conserved 'IXI' sequence and the unstructured and flexible C-terminal extension encompassing the last 12 amino acids.

Fig. 1B Crystal structure of the Methanococcus jannaschii Hsp16.5 24-mer oligomer showing its large central cavity [20]. Each colour represents an individual subunit within the oligomer. Reprinted with permission from [20].

Fig. 1C X-ray crystal structure of the ACD and C-terminal region of $\alpha \mathrm{Bc}$ without its flexible C-terminal extension [12]. The $\alpha \mathrm{Bc}$ dimer is shown in which the six $\beta$-strands of each ACD are arranged in an immunoglobulin-like fold. The intra-dimer contacts arise between $\beta$-strands 6 and 7 of each subunit, arranged in an antiparallel (AP) manner. The inter-dimer interaction is also shown in which an $\alpha \mathrm{Bc}$ peptide from the $\mathrm{C}$-terminal region of one subunit encompassing a palindromic nine amino acid sequence (residues 156 to 164), including the 'IXI' sequence (IPI; residues 159 to 161), interacts with the fourth and eighth $\beta$-strands of the adjacent $\alpha$ Bc subunit. Adapted and used with permission from [12].

\section{Fig. 2 The chaperone mechanism of sHsps}

Multiple partially-folded protein intermediate states populate the folding/unfolding pathway of a protein. The mechanism by which sHsps, such as $\alpha \mathrm{B}-\mathrm{c}$, prevent target protein aggregation (either amorphous or fibrillar) is dictated by the conformational stability and exposed hydrophobicity of the precursor protein intermediates. High affinity interactions occur with highly destabilised intermediates (which exceed the threshold of binding) and these are sequestered into stable high molecular mass complexes. Target proteins in these complexes can be re-folded through the action of other ATP-dependent chaperones or shuttled for degradation or via chaperone-mediated autophagy. Alternatively, weak, transient interactions occur with more stable protein intermediates, which re-direct them back to the folding pathway so as to facilitate their re-folding. sHsps can also interact with pre-fibrillar and fibrillar aggregates formed by target proteins. By binding to these species sHsps stabilise them preventing their further elongation and fibril fragmentation and secondary nucleation events, which can be the main source of toxic oligomeric species formed during amyloid fibrillar aggregation. (Adapted from [95]).

\section{Fig 3. The effect of phosphorylation on sHsps in cells}

Under basal conditions in the cell sHsps act to maintain proteostasis by buffering against protein aggregation of target proteins. Conditions of cellular stress (e.g. a change in $\mathrm{pH}$, oxidative stress or increase in temperature) are sensed by the cell, triggering a signalling pathway that results in the activation of protein kinases, including mitogen activated protein (MAP) kinases which can phosphorylate sHsps, such as $\alpha \mathrm{B}-\mathrm{c}$ and Hsp27. Phosphorylation of sHsps decreases their oligomeric size and causes some 
phosphorylated sHsps to be translocated to the nucleus. In doing so, phosphorylation boosts the chaperone activity of sHsps against target proteins in danger of aggregating and precipitating as a result of the cellular stress. Prolonged exposure to stress leads to the activation of the transcription factor heat-shock factor 1 (HSF1), which self- associates into trimers and then relocates to the nucleus, stimulating transcription of heat-shock response genes including the sHsps Hsp27, $\alpha \mathrm{Bc}$ and Hsp22. Newly translated sHsps oligomerise with existing sHsps leading to the formation of a heterogeneous pool of sHsp oligomers (including phosphorylated and non-phosphorylated forms), which maximises their possible binding interactions with intracellular target proteins to prevent their aggregation. The Venn diagram in the centre represents the group of aggregationprone target proteins with which the non-phosphorylated (blue), phosphorylated (red) or heterogeneous (purple) sHsp oligomers interact.

Fig. 4. Homology model of the human $\alpha \mathrm{Bc}$ monomer showing approximate locations of naturally-occurring, disease-causing mutations. Adapted and reused with permission from [264]. Copyright (2014) American Chemical Society. 


\section{References}

[1] Baldwin, A. J., Knowles, T. P., Tartaglia, G. G., Fitzpatrick, A. W., Devlin, G. L., Shammas, S. L., Waudby, C. A., Mossuto, M. F., Meehan, S., Gras, S. L., Christodoulou, J., Anthony-Cahill, S. J., Barker, P. D., Vendruscolo, M. and Dobson, C. M. (2011). Metastability of native proteins and then phenomenon of amyloid formation. J. Am. Chem. Soc. 133, 14160-14163.

[2] Ciryam, P., Tartaglia, G. G., Morimoto, R. I., Dobson, C. M. and Vendruscolo, M. (2013). Widespread aggregation and neurodegenerative diseases are associated with supersaturated proteins. Cell Rep. 5, 781-790.

[3] Hilton, G. R., Lioe, H., Stengel, F., Baldwin, A. J. and Benesch, J. L. P. (2013). Small heat-shock proteins: paramedics of the cell. Top. Curr. Chem. 328, 69-98.

[4] Laskowska, E., Matuszewska, E. and Kuczynska-Wisnik, D. (2010). Small heat-shock proteins and protein-misfolding diseases. Curr. Pharm. Biotechnol. 11, 146-157.

[5] Mymrikov, E. V., Seit-Nebi, A. S. and Gusev, N. B. (2011). Large potentials of small heat shock proteins. Physiol. Rev. 91, 1123-1159.

[6] Carra, S., Rusmini, P., Crippa, V., Giorgetti, E., Boncoraglio, A., Cristofani, R., Naujock, M., Meister, M., Minoia, M., Kampinga, H. H. and Poletti, A. (2013). Different anti-aggregation and pro-degradative functions of the members of the mammalian sHSP family in neurological disorders. Philos. Trans. R. Soc. Lond. B. Biol. Sci. 368, 20110409.

[7] Basha, E., O'Neill, H. and Vierling, E. (2012). Small heat shock proteins and $\alpha-$ crystallins: dynamic proteins with flexible functions. Trends Biochem. Sci. 37, 106117.

[8] Wyatt, A. R., Yerbury, J. J., Ecroyd, H. and Wilson, M. R. (2013). Extracellular chaperones and proteostasis. Annu. Rev. Biochem. 82, 295-322.

[9] Humphreys, D. T., Carver, J. A., Easterbrook-Smith, S. B. and Wilson, M. R. (1999). Clusterin has chaperone-like activity similar to that of small heat shock proteins. J. Biol. Chem. 274, 6875-6881.

[10] Poon, S., Easterbrook-Smith, S. B., Rybchyn, M. S., Carver, J. A. and Wilson, M. R. (2000). Clusterin is an ATP-independent chaperone with very broad substrate specificity that stabilizes stressed proteins in a folding-competent state. Biochemistry (Mosc). 39, 15953-15960.

[11] Delbecq, S. P. and Klevit, R. E. (2013). One size does not fit all: the oligomeric states of $\alpha B$-crystallin. FEBS Lett. 587, 1073-1080.

[12] Hilton, G. R., Hochberg, G. K. A., Laganowsky, A., McGinningle, S. I., Baldwin, A. J. and Benesch, J. L. P. (2013). C-terminal interactions mediate the quaternary dynamics of $\alpha$ B-crystallin. Philos. Trans. R. Soc. Lond. B. Biol. Sci. 368, 1-13.

[13] Treweek, T. M., Ecroyd, H., Williams, D. M., Meehan, S., Carver, J. A. and Walker, M. J. (2007). Site-directed mutations in the C-terminal extension of human aBcrystallin affect chaperone function and block amyloid fibril formation. PLoS One e1046, 1-10.

[14] Haley, D. A., Horwitz, J. and Stewart, P. L. (1998). The small heat-shock protein, aBcrystallin, has a variable quaternary structure. J. Mol. Biol. 277, 27-35.

[15] Bova, M. P., Ding, L.-L., Horwitz, J. and Fung, B. K.-K. (1997). Subunit exchange of alphaA-crystallin. J. Biol. Chem. 272, 29511-29517.

[16] Carver, J. A., Aquilina, J. A., Truscott, R. J. W. and Ralston, G. B. (1992). Identification by ${ }^{1} \mathrm{H}$ NMR spectroscopy of flexible C-terminal extensions in bovine lens $\alpha$-crystallin. FEBS Lett. 311, 143-149. 
[17] Carver, J. A. and Lindner, R. A. (1998). NMR spectroscopy of alpha-crystallin. Insights into the structure, interactions and chaperone action of small heat-shock proteins. Int. J. Biol. Macromol. 22, 197-209.

[18] Carver, J. A. (1999). Probing the structure and interactions of crystallin proteins by NMR spectroscopy. Prog. Retin. Eye Res. 18, 431-462.

[19] Esposito, G., Viglino, P., Fogolari, F., Gaestel, M. and Carver, J. A. (1998). Selective NMR experiments on macromolecules: Implementation and analysis of QUIETNOESY. J. Magn. Reson. 132, 204-213.

[20] Kim, K. K., Kim, D. R. and Kim, S. H. (1998). Crystal structure of a small heat-shock protein. Nature 394, 595-599.

[21] van Montfort, R. L. M., Basha, E., Friedrich, K. L., Slingsby, C. and Vierling, E. (2001). Crystal structure and assembly of a eukaryotic small heat shock protein. Nat. Struct. Biol. 8, 1025-1030.

[22] Aquilina, J. A., Benesch, J. L., Bateman, O. A., Slingsby, C. and Robinson, C. V. (2003). Polydispersity of a mammalian chaperone: Mass spectrometry reveals the population of oligomers in alphaB-crystallin. Proc. Natl. Acad. Sci. U. S. A. 100, 10611-10616.

[23] Bagnéris, C., Bateman, O. A., Naylor, C. E., Cronin, N., Boelens, W. C., Keep, N. H. and Slingsby, C. (2009). Crystal structures of alpha-crystallin domain dimers of alphaB-crystallin and Hsp20. J. Mol. Biol. 392, 1242-1252.

[24] Baranova, E. V., Weeks, S. D., Beelen, S., Bukach, O. V., Gusev, N. B. and Strelkov, S. V. (2011). Three-dimensional structure of $\alpha$-crystallin domain dimers of human small heat shock proteins HSPB1 and HSPB6. J. Mol. Biol. 411, 110-122.

[25] Laganowsky, A., Benesch, J. L. P., Landau, M., Ding, L. L., Sawaya, M. R., Cascio, D., Huang, Q. L., Robinson, C. V., Horwitz, J. and Eisenberg, D. (2010). Crystal structures of truncated alphaA- and alphaB-crystallins reveal structural mechanisms of polydispersity important for eye lens function. Protein Sci. 19, 1031-1043.

[26] Hochberg, G. K. A., Ecroyd, H., Liu, C., Cox, D., Cascio, D., Sawaya, M. R., Collier, M. P., Stroud, J., Carver, J. A., Baldwin, A. J., Robinson, C. V., Eisenberg, D. S., Benesch, J. L. P. and Laganowsky, A. (2014). The structured core domain of alphaBcrystallin can prevent amyloid fibrillation and associated toxicity. Proc. Natl. Acad. Sci. U. S. A. 111, E1562-1570.

[27] Jehle, S., van Rossum, B., Stout, J. R., Noguchi, S. M., Falber, K., Rehbein, K., Oschkinat, H., Klevit, R. E. and Rajagopal, P. (2009). $\alpha$ B-crystallin: a hybrid solidstate/solution-state NMR investigation reveals structural aspects of the heterogeneous oligomer. J. Mol. Biol. 385, 1481-1497.

[28] Jehle, S., Vollmar, B. S., Bardiaux, B., Dove, K. K., Rajagopal, P., Gonen, T., Oschkinat, H. and Klevit, R. E. (2011). N-terminal domain of alphaB-crystallin provides a conformational switch for multimerization and structural heterogeneity. Proc. Natl. Acad. Sci. U. S. A. 108, 6409-6414.

[29] Hochberg, G. K. and Benesch, J. L. (2014). Dynamical structure of $\alpha B$-crystallin. Prog. Biophys. Mol. Biol. 115, 11-20.

[30] Haley, D. A., Bova, M. P., Huang, Q. L., McHaourab, H. S. and Stewart, P. L. (2000). Small heat-shock protein structures reveal a continuum from symmetric to variable assemblies. J. Mol. Biol. 298, 261-272.

[31] Meehan, S., Berry, Y., Luisi, B., Dobson, C. M., Carver, J. A. and MacPhee, C. E. (2004). Amyloid fibril formation by lens crystallin proteins and its implications for cataract formation. J. Biol. Chem. 279, 3413-3419.

[32] Meehan, S., Knowles, T. P., Baldwin, A. J., Smith, J. F., Squires, A. M., Clements, P., Treweek, T. M., Ecroyd, H., Tartaglia, G. G., Vendruscolo, M., MacPhee, C. E., 
Dobson, C. M. and Carver, J. A. (2007). Characterisation of amyloid fibril formation by small heat-shock chaperone proteins human alphaA-, alphaB- and R120G alphaBcrystallins. J. Mol. Biol. 372, 470-484.

[33] Horwitz, J., Bova, M. P., Ding, L. L., Haley, D. A. and Stewart, P. L. (1999). Lens $\alpha-$ crystallin: function and structure. Eye 13, 403-408.

[34] Peschek, J., Braun, N., Franzmann, T. M., Georgalis, Y., Haslbeck, M., Weinkauf, S. and Buchner, J. (2009). The eye lens chaperone alpha-crystallin forms defined globular assemblies. Proc. Natl. Acad. Sci. U. S. A. 106, 13272-13277.

[35] Carver, J. A., Aquilina, J. A. and Truscott, R. J. W. (1994). A possible chaperone-like quaternary structure for alpha-crystallin. Exp. Eye Res. 59, 231-234.

[36] Raman, B. and Rao, C. M. (1994). Chaperone-like activity and quaternary structure of alpha-crystallin. J. Biol. Chem. 269, 27264-27268.

[37] Ecroyd, H. and Carver, J. A. (2009). Crystallin proteins and amyloid fibrils. Cell. Mol. Life Sci. 66, 62-81.

[38] Regini, J. W., Grossmann, J. G., Burgio, M. R., Malik, N. S., Koretz, J. F., Hodson, S. A. and Elliott, G. F. (2004). Structural changes in alpha-crystallin and whole eye lens during heating, observed by low-angle X-ray diffraction. J. Mol. Biol. 336, 1185 1194.

[39] Regini, J. W., Grossmann, J. G., Timmins, P., Harding, J. J., Quantock, A. J., Hodson, S. A. and Elliott, G. F. (2007). X-ray- and neutron-scattering studies of $\alpha$-crystallin and evidence that the target protein sits in the fenestrations of the $\alpha$-crystallin shell. Invest. Ophthalmol. Vis. Sci. 48, 2695-2700.

[40] Clarke, M. J., Artero, J. B., Moulin, M., Callow, P., Carver, J. A., Griffiths, P. C., Haertlein, M., Harding, J. J., Meek, K. M., Timmins, P. and Regini, J. W. (2010). Investigation of $\gamma \mathrm{E}$-crystallin target protein binding to bovine lens alpha-crystallin by small-angle neutron scattering. Biochim. Biophys. Acta 1800, 392-397.

[41] Spinozzi, F., Mariani, P., Rustichelli, F., Amenitsch, H., Bennardini, F., Mura, G. M., Coi, A. and Ganadu, M. L. (2006). Temperature dependence of chaperone-like activity and oligomeric state of alphaB-crystallin. Biochim. Biophys. Acta 1764, $677-$ 687.

[42] Skouri-Panet, F., Quevillon-Cheruel, S., Michiel, M., Tardieu, A. and Finet, S. (2006). sHSPs under temperature and pressure: The opposite behaviour of lens alphacrystallins and yeast HSP26. Biochim. Biophys. Acta 1764, 372-383.

[43] Regini, J. W., Ecroyd, H., Meehan, S., Bremmell, K., Clarke, M. J., Lammie, D., Wess, T. and Carver, J. A. (2010). The interaction of unfolding $\alpha$-lactalbumin and malate dehydrogenase with the molecular chaperone $\alpha \mathrm{B}$-crystallin: a light and X-ray scattering investigation. Mol. Vis. 16, 2446-2456.

[44] Bhat, S. P. and Nagineni, C. N. (1989). AlphaB-subunit of lens specific alphacrystallin is present in other ocular and non-ocular tissue. Biochem. Biophys. Res. Commun. 158, 319-325.

[45] Horwitz, J. (1992). alpha-Crystallin can function as a molecular chaperone. Proc. Natl. Acad. Sci. U. S. A. 89, 10449-10453.

[46] Ingolia, T. D. and Craig, E. A. (1982). Four small Drosophila heat shock proteins are related to each other and to mammalian alpha-crystallin. Proc. Natl. Acad. Sci. U. S. A. 79, 2360-2364.

[47] McAvoy, J. W., Chamberlain, C. G., de Iongh, R. U., Hales, A. M. and Lovicu, F. J. (1999). Lens development. Eye 13, 425-437.

[48] Wistow, G. J. and Piatigorsky, J. (1988). Lens crystallins: the evolution and expression of proteins for a highly specialized tissue. Annu. Rev. Biochem. 57, 479504. 
[49] Bassnett, S. (2002). Lens organelle degradation. Exp. Eye Res. 74, 1-6.

[50] Bassnett, S. (2009). On the mechanism of organelle degradation in the vertebrate lens. Exp. Eye Res. 88, 133-139.

[51] Piatigorsky, J. (1981). Lens differentiation in vertebrates. A review of cellular and molecular features. Differentiation 19, 134-153.

[52] Tardieu, A. (1998). alpha-Crystallin quaternary structure and interactive properties control eye lens transparency. Int. J. Biol. Macromol. 22, 211-217.

[53] Augusteyn, R. C. (2010). On the growth and internal structure of the human lens. Exp. Eye Res. 90, 643-654.

[54] Fagerholm, P. P., Philipson, B. T. and Lindstrom, B. (1981). Normal human lens distribution of protein. Exp. Eye Res. 33, 615-620.

[55] Frederikse, P. H. (2000). Amyloid-like protein structure in mammalian ocular lenses. Curr. Eye Res. 20, 462-468.

[56] Schachar, R. A. and Solin, S. A. (1975). Microscopic protein structure of lens with a theory for cataract formation as determined by Raman spectroscopy of intact bovine lenses. Invest. Ophthalmol. 14, 380-396.

[57] Yu, N. T. and East, E. J. (1975). Laser Raman spectroscopic studies of ocular lens and its isolated protein fractions. J. Biol. Chem. 250, 2196-2202.

[58] Delaye, M. and Tardieu, A. (1983). Short-range order of crystallin proteins accounts for eye lens transparency. Nature 302, 415-417.

[59] Bloemendal, H. (1977). The vertebrate eye lens. Science 197, 127-138.

[60] Brady, J. P., Garland, D., Duglas-Tabor, Y., Robison, W. G. J., Groome, A. and Wawrousek, E. F. (1997). Targeted disruption of the mouse alphaA-crystallin gene induces cataract and cytoplasmic inclusion bodies containing the small heat shock protein alphaB-crystallin. Proc. Natl. Acad. Sci. U. S. A. 94, 884-889.

[61] Horwitz, J. (2000). The function of alpha-crystallin in vision. Semin. Cell Dev. Biol. 11, 53-60.

[62] Hsu, C. D., Kymes, S. and Petrash, J. M. (2006). A transgenic mouse model for human autosomal dominant cataract. Invest. Ophthalmol. Vis. Sci. 47, 2036-2044.

[63] Sun, T. X. and Liang, J. J. (1998). Intermolecular exchange and stabilization of recombinant human alphaA- and alphaB-crystallin. J. Biol. Chem. 273, 286-290.

[64] Bhat, S. P., Horwitz, J., Srinivasan, A. and Ding, L. (1991). AlphaB-crystallin exists as an independent protein in the heart and in the lens. Eur. J. Biochem. 202, 775-781.

[65] Nagineni, C. N. and Bhat, S. P. (1989). AlphaB-crystallin is expressed in kidney epithelial cell lines and not in fibroblasts. FEBS Lett. 249, 89-94.

[66] May, C. A., Arnold, B., Welge-Lussen, U., Arnold, W., Bloemendal, H. and LutjenDrecoll, E. (1998). AlphaB-crystallin in the mammalian inner ear. ORL. J.

Otorhinolaryngol. Relat. Spec. 60, 121-125.

[67] May, C. A., Lussen, U. W., Junemann, A., Bloemendal, H. and Lutjen-Drecoll, E. (2000). AlphaB-crystallin in lacrimal gland duct and tears. Curr. Eye Res. 21, 588594.

[68] Srinivasan, A. N., Nagineni, C. N. and Bhat, S. P. (1992). alphaA-Crystallin is expressed in non-ocular tissues. J. Biol. Chem. 267, 23337-23341.

[69] Bhat, S. P. (2003). Crystallins, genes and cataract. Prog. Drug Res. 60, 205-262.

[70] Parcellier, A., Schmitt, E., Brunet, M., Hammann, A., Solary, E. and Garrido, C. (2005). Small heat shock proteins HSP27 and alphaB-crystallin: Cytoprotective and oncogenic functions. Antioxid. Redox Signal. 7, 404-413.

[71] Dasgupta, S., Hohman, T. C. and Carper, D. (1992). Hypertonic stress induces alphaB-crystallin expression. Exp. Eye Res. 54, 461-470. 
[72] Derham, B. K. and Harding, J. J. (1999). alpha-Crystallin as a molecular chaperone. Prog. Retin. Eye Res. 18, 463-509.

[73] Klemenz, R., Frohl, E., Steiger, R. H., Schafer, R. and Aoyama, A. (1991). AlphaBcrystallin is a small heat shock protein. Proc. Natl. Acad. Sci. U. S. A. 88, 3652-3656.

[74] van den Ijssel, P. R., Overkamp, P., Knauf, U., Gaestel, M. and de Jong, W. W. (1994). AlphaA-crystallin confers cellular thermoresistance. FEBS Lett. 355, 54-56.

[75] Arrigo, A. P. (1998). Small stress proteins: chaperones that act as regulators of intracellular redox state and programmed cell death. Biol. Chem. 379, 19-26.

[76] Wang, K. Y. and Spector, A. (1995). Alpha-crystallin can act as a chaperone under conditions of oxidative stress. Invest. Ophthalmol. Vis. Sci. 36, 311-321.

[77] Laudanski, K. and Wyczechowska, D. (2006). The distinctive role of small heat shock proteins in oncogenesis. Arch. Immunol. Ther. Exp. (Warsz). 54, 103-111.

[78] Ousman, S. S., Tomooka, B. H., van Noort, J. M., Wawrousek, E. F., O'Connor, K. C., Hafler, D. A., Sobel, R. A., Robinson, W. H. and Steinman, L. (2007). Protective and therapeutic role for alphaB-crystallin in autoimmune demyelination. Nature 448, 474-479.

[79] Zoubeidi, A. and Gleave, M. (2012). Small heat shock proteins in cancer therapy and prognosis. Int. J. Biochem. Cell Biol. 44, 1646-1656.

[80] Kato, K., Shinohara, H., Goto, S., Inaguma, Y., Morishita, R. and Asano, T. (1992). Copurification of small heat shock protein with alphaB-crystallin from human skeletal muscle. J. Biol. Chem. 267, 7718-7725.

[81] Inaguma, Y., Goto, S., Shinohara, H., Hasegawa, K., Ohshima, K. and Kato, K. (1993). Physiological and pathological changes in levels of the two small stress proteins, HSP27 and alphaB-crystallin, in rat hindlimb muscles. J. Biochem. (Tokyo). 114, 378-384.

[82] Sakuma, K., Watanabe, K., Totsuka, T. and Kato, K. (1998). Pathological changes in levels of three small stress proteins, alphaB-crystallin, HSP 27 and p20, in the hindlimb muscles of dy mouse. Biochim. Biophys. Acta 1406, 162-168.

[83] Head, M. W., Corbin, E. and Goldman, J. E. (1993). Overexpression and abnormal modification of the stress proteins alphaB-crystallin and HSP27 in Alexander disease. Am. J. Pathol. 143, 1743-1753.

[84] Arrigo, A. P., Simon, S., Gibert, B., Kretz-Remy, C., Nivon, M., Czekalla, A., Guillet, D., Moulin, M., Diaz-Latoud, C. and Vicart, P. (2007). Hsp27 (HspB1) and alphaBcrystallin (HspB5) as therapeutic targets. FEBS Lett. 581, 3665-3674.

[85] Zantema, A., Verlaan-De Vries, M., Maasdam, D., Bol, S. and van der Eb, A. (1992). Heat shock protein 27 and alphaB-crystallin can form a complex, which dissociates by heat shock. J. Biol. Chem. 267, 12936-12941.

[86] Simon, S., Dimitrova, V., Gibert, B., Virot, S., Mounier, N., Nivon, M., Kretz-Remy, C., Corset, V., Mehlen, P. and Arrigo, A. P. (2013). Analysis of the dominant effects mediated by wild type or R120G mutant of alphaB-crystallin (HspB5) towards Hsp27 (HspB1). PLoS One 8, e70545.

[87] Bova, M. P., Mchaourab, H. S., Han, Y. and Fung, B. K.-K. (2000). Subunit exchange of small heat shock proteins. Analysis of oligomer formation of alphaA-crystallin and Hsp27 by fluorescence resonance energy transfer and site-directed trucations. J. Biol. Chem. 275, 1035-1042.

[88] Bukach, O. V., Glukhova, A. E., Seit-Nebi, A. S. and Gusev, N. B. (2009). Heterooligomeric complexes formed by human small heat shock proteins HspB1 (Hsp27) and HspB6 (Hsp20). Biochim. Biophys. Acta 1794, 486-495. 
[89] Aquilina, J. A., Shrestha, S., Morris, A. M. and Ecroyd, H. (2013). Structural and functional aspects of hetero-oligomers formed by the small heat shock proteins alphaB-crystallin and HSP27. J. Biol. Chem. 288, 13602-13609.

[90] Sugiyama, Y., Suzuki, A., Kishikawa, M., Akutsu, R., Hirose, T., Waye, M. M., Tsui, S. K., Yoshida, S. and Ohno, S. (2000). Muscle develops a specific form of small heat shock protein complex composed of MKBP/HSPB2 and HSPB3 during mitogenic differentiation. J. Biol. Chem. 275, 1095-1104.

[91] den Engelsman, J., Boros, S., Dankers, P. Y., Kamps, B., Vree Egberts, W. T., Bode, C. S., Lane, L. A., Aquilina, J. A., Benesch, J. L., Robinson, C. V., de Jong, W. W. and Boelens, W. C. (2009). The small heat-shock proteins HSPB2 and HSPB3 form well-defined heterooligomers in a unique 3 to 1 subunit ratio. J. Mol. Biol. 393, 1022 1032.

[92] Kato, K., Hasegawa, K., Goto, S. and Inaguma, Y. (1994). Dissociation as a result of phosphorylation of an aggregated form of the small stress protein, hsp27. J. Biol. Chem. 269, 11274-11278.

[93] Datskevich, P. N., Mymrikov, E. V. and Gusev, N. B. (2012). Utilization of fluorescent chimeras for investigation of heterooligomeric complexes formed by human small heat shock proteins. Biochimie 94, 1794-1804.

[94] Datskevich, P. N., Mymrikov, E. V., Sluchanko, N. N., Shemetov, A. A., Sudnitsyna, M. V. and Gusev, N. B. (2012). Expression, purification and some properties of fluorescent chimeras of human small heat shock proteins. Protein Expres. Purif. 82, 45-54.

[95] Datta, S. A. and Rao, C. M. (2000). Packing-induced conformational and functional changes in the subunits of alpha-crystallin. J. Biol. Chem. 275, 41004-41010.

[96] Narberhaus, F. (2002). $\alpha$-Crystallin-type heat shock proteins: Socializing minichaperones in the context of a multichaperone network. Microbiol. Mol. Biol. Rev. 66, 64-93.

[97] Lindner, R. A., Kapur, A. and Carver, J. A. (1997). The interaction of the molecular chaperone, alpha-crystallin, with molten globule states of bovine alpha-lactalbumin. J. Biol. Chem. 272, 27722-27729.

[98] Hatters, D. M., Lindner, R. A., Carver, J. A. and Howlett, G. J. (2001). The molecular chaperone, alpha-crystallin, inhibits amyloid formation by Apolipoprotein C-II. J. Biol. Chem. 276, 33755-33761.

[99] Lindner, R. A., Treweek, T. M. and Carver, J. A. (2001). The molecular chaperone alpha-crystallin is in kinetic competition with aggregation to stabilize a monomeric molten-globule form of alpha-lactalbumin. Biochem. J. 354, 79-87.

[100] Kulig, M. and Ecroyd, H. (2012). The small heat-shock protein alphaB-crystallin uses different mechanisms of chaperone action to prevent the amorphous versus fibrillar aggregation of alpha-lactalbumin. Biochem. J. 448, 343-352.

[101] Giese, K. C., Basha, E., Catague, B. Y. and Vierling, E. (2005). Evidence for an essential function of the $\mathrm{N}$ terminus of a small heat shock protein in vivo, independent of in vitro chaperone activity. Proc. Natl. Acad. Sci. U. S. A. 102, 18896-18901.

[102] Stromer, T., Fischer, E., Richter, K., Haslbeck, M. and Buchner, J. (2004). Analysis of the regulation of the molecular chaperone Hsp26 by temperature-induced dissociation. J. Biol. Chem. 279, 11222-11228.

[103] Aquilina, J. A. and Watt, S. J. (2007). The N-terminal domain of alphaB-crystallin is protected from proteolysis by bound substrate. Biochem. Biophys. Res. Commun. 353, 1115-1120.

[104] Peschek, J., Braun, N., Rohrberg, J., Back, K. C., Kriehuber, T., Kastenmuller, A., Weinkauf, S. and Buchner, J. (2013). Regulated structural transitions unleash the 
chaperone activity of alphaB-crystallin. Proc. Natl. Acad. Sci. U. S. A. 110, E37803789.

[105] Bhattacharyya, J., Padmanabha Udupa, E. G., Wang, J. and Sharma, K. K. (2006). Mini-alphaB crystallin: a functional element of alphaB-crystallin with chaperone-like activity. Biochemistry (Mosc). 45, 3069-3076.

[106] Sharma, K. K., Kaur, H. and Kester, K. (1997). Functional elements in molecular chaperone alpha-crystallin: identification of binding sites in alpha B-crystallin. Biochem. Biophys. Res. Commun. 239, 217-222.

[107] Jehle, S., Rajagopal, P., Bardiaux, B., Markovic, S., Kuehne, R., Stout, J. R., Higman, V. A., Klevit, R. E., van Rossum, B.-J. and Oschkinat, H. (2010). Solid-state NMR and SAXS studies provide a structural basis for the activation of alphaB-crystallin oligomers. Nat. Struct. Mol. Biol. 17, 1037-U1.

[108] Feil, I. K., Malfois, M., Hendle, J., van der Zant, H. and Svergun, D. I. (2001). A novel quaternary structure of the dimeric $\alpha$-crystallin domain with chaperone-like activity. J. Biol. Chem. 276, 12024-12029.

[109] Sharma, K. K., Kumar, R. S., Kumar, G. S. and Quinn, P. T. (2000). Synthesis and characterization of a peptide identified as a functional element in $\alpha \mathrm{A}$-crystallin. J. Biol. Chem. 275, 3767-3771.

[110] Shi, J., Koteiche, H. A., McDonald, E. T., Fox, T. L., Stewart, P. L. and McHaourab, H. S. (2013). Cryoelectron microscopy analysis of small heat shock protein 16.5 (Hsp16.5) complexes with T4 lysozyme reveals the structural basis of multimode binding. J. Biol. Chem. 288, 4819-4830.

[111] Koteiche, H. A. and Mchaourab, H. S. (2003). Mechanism of chaperone function in small heat-shock proteins: Phosphorylation-induced activation of two-mode binding in alphaB-crystallin. J. Biol. Chem. 278, 10361-10367.

[112] Shinohara, H., Inaguma, Y., Goto, S., Inagaki, T. and Kato, K. (1993). AlphaBcrystallin and HSP28 are enhanced in the cerebral cortex of patients with Alzheimer's disease. J. Neurol. Sci. 119, 203-208.

[113] Renkawek, K., Voorter, C. E., Bosman, G. J., van Workum, F. P. and de Jong, W. W. (1994). Expression of alphaB-crystallin in Alzheimer's disease. Acta Neuropathol. (Berl). 87, 155-160.

[114] Rekas, A., Jankova, L., Thorn, D. C., Cappai, R. and Carver, J. A. (2007). Monitoring the prevention of amyloid fibril formation by alpha-crystallin. FEBS J. 274, 62906304.

[115] Waudby, C. A., Knowles, T. P. J., Devlin, G. L., Skepper, J. N., Ecroyd, H., Carver, J. A., Welland, M. E., Christodoulou, J., Dobson, C. M. and Meehan, S. (2010). The interaction of alphaB-crystallin with mature alpha-synuclein amyloid fibrils inhibits their elongation. Biophys. J. 98, 843-851.

[116] Shammas, S. L., Waudby, C. A., Wang, S., Buell, A. K., Knowles, T. P., Ecroyd, H., Welland, M. E., Carver, J. A., Dobson, C. M. and Meehan, S. (2011). Binding of the molecular chaperone alphaB-crystallin to A-beta amyloid fibrils inhibits fibril elongation. Biophys. J. 101, 1681-1689.

[117] Binger, K. J., Ecroyd, H., Yang, S., Carver, J. A., Howlett, G. J. and Griffin, M. D. (2013). Avoiding the oligomeric state: alphaB-crystallin inhibits fragmentation and induces dissociation of apolipoprotein C-II amyloid fibrils. FASEB J. 27, 1214-1222.

[118] Knowles, T. P., Waudby, C. A., Devlin, G. L., Cohen, S. I., Aguzzi, A., Vendruscolo, M., Terentjev, E. M., Welland, M. E. and Dobson, C. M. (2009). An analytical solution to the kinetics of breakable filament assembly. Science 326, 1533-1537.

[119] Esposito, G., Garvey, M., Alverdi, V., Pettirossi, F., Corazza, A., Fogolari, F., Polano, M., Mangione, P. P., Giorgetti, S., Stoppini, M., Rekas, A., Bellotti, V., Heck, A. J. 
and Carver, J. A. (2013). Monitoring the interaction between beta2-microglobulin and the molecular chaperone alphaB-crystallin by NMR and mass spectrometry: alphaBcrystallin dissociates beta2-microglobulin oligomers. J. Biol. Chem. 288, 1784417858.

[120] Sharma, K. K. and Ortwerth, B. J. (1995). Effect of cross-linking on the chaperonelike function of alpha crystallin. Exp. Eye Res. 61, 413-421.

[121] Augusteyn, R. C. (2004). Dissociation is not required for alpha-crystallin's chaperone function. Exp. Eye Res. 79, 781-784.

[122] Aquilina, J. A., Benesch, J. L., Ding, L. L., Yaron, O., Horwitz, J. and Robinson, C. V. (2005). Subunit exchange of polydisperse proteins: mass spectrometry reveals consequences of alphaA-crystallin truncation. J. Biol. Chem. 280, 14485-14491.

[123] Ito, H., Iida, K., Kamei, K., Iwamoto, I., Inaguma, Y. and Kato, K. (1999). AlphaBcrystallin in the rat lens is phosphorylated at an early post-natal age. FEBS Lett. 446, 269-272.

[124] Kilby, G. W., Carver, J. A., Zhu, J. L., Sheil, M. M. and Truscott, R. J. (1995). Loss of the C-terminal serine residue from bovine beta B2-crystallin. Exp. Eye Res. 60, 465-469.

[125] Carver, J. A., Nicholls, K. A., Aquilina, J. A. and Truscott, R. J. (1996). Age-related changes in bovine alpha-crystallin and high-molecular-weight protein. Exp. Eye Res. 63, 639-647.

[126] Truscott, R. J. W. and Zhu, X. (2010). Presbyopia and cataract: A question of heat and time. Prog. Retin. Eye Res. 29, 487-499.

[127] Hayes, V. H., Devlin, G. and Quinlan, R. A. (2008). Truncation of alphaB-crystallin by the myopathy-causing Q151X mutation significantly destabilizes the protein leading to aggregate formation in transfected cells. J. Biol. Chem. 283, 10500-10512.

[128] Hains, P. G. and Truscott, R. J. W. (2010). Age-dependent deamidation of lifelong proteins in the human lens. Invest. Ophthalmol. Vis. Sci. 51, 3107-3114.

[129] Lampi, K. J., Wilmarth, P. A., Murray, M. R. and David, L. L. (2014). Lens $\beta$ crystallins: The role of deamidation and related modifications in aging and cataract. Prog. Biophys. Mol. Biol. 115, 21-31.

[130] Wilmarth, P. A., Tanner, S., Dasari, S., Nagalla, S. R., Riviere, M. A., Bafna, V., Pevzner, P. A. and David, L. L. (2006). Age-related changes in human crystallins determined from comparative analysis of post-translational modifications in young and aged lens: does deamidation contribute to crystallin insolubility? J. Proteome Res. 5, 2554-2566.

[131] Stevens, V. J., Rouzer, C. A., Monnier, V. and Cerami, A. (1978). Diabetic cataract formation: Potential role of glycosylation of lens crystallins (nonenzymatic glycosylation/sulfhydryl oxidation). Proc. Natl. Acad. Sci. U. S. A. 75, 2918-2922.

[132] Blakytny, R., Carver, J. A., Harding, J. J., Kilby, G. W. and Sheil, M. M. (1997). A spectroscopic study of glycated bovine alpha-crystallin: investigation of flexibility of the C-terminal extension, chaperone activity and evidence for diglycation. Biochim. Biophys. Acta 1343, 299-315.

[133] Arrigo, A. P. and Welch, W. J. (1987). Characterization and purification of the small 28,000-dalton mammalian heat shock protein. J. Biol. Chem. 262, 15359-15369.

[134] Landry, J., Chretien, P., Laszlo, A. and Lambert, H. (1991). Phosphorylation of HSP27 during development and decay of thermotolerance in Chinese hamster cells. J. Cell. Physiol. 147, 93-101.

[135] Kato, K., Goto, S., Inaguma, Y., Hasegawa, K., Morishita, R. and Asano, T. (1994). Purification and characterization of a $20-\mathrm{kDa}$ protein that is highly homologous to alphaB-crystallin. J. Biol. Chem. 269, 15302-15309. 
[136] Ito, H., Okamoto, K., Nakayama, H., Isobe, T. and Kato, K. (1997). Phosphorylation of alphaB-crystallin in response to various types of stress. J. Biol. Chem. 272, 2993429941.

[137] van den Ijssel, P. R., Overkamp, P., Bloemendal, H. and de Jong, W. W. (1998). Phosphorylation of alphaB-crystallin and HSP27 is induced by similar stressors in HeLa cells. Biochem. Biophys. Res. Commun. 247, 518-523.

[138] Voorter, C. E., de Haard-Hoekman, W. A., Roersma, E. S., Meyer, H. E., Bloemendal, H. and de Jong, W. W. (1989). The in vivo phosphorylation sites of bovine alphaB-crystallin. FEBS Lett. 259, 50-52.

[139] Smith, J. B., Sun, Y., Smith, D. L. and Green, B. (1992). Identification of the posttranslational modifications of bovine lens alphaB-crystallins by mass spectrometry. Protein Sci. 1, 601-608.

[140] Kato, K., Ito, H., Kamei, K., Inaguma, Y., Iwamoto, I. and Saga, S. (1998). Phosphorylation of alphaB-crystallin in mitotic cells and identification of enzymatic activities responsible for phosphorylation. J. Biol. Chem. 273, 28346-28354.

[141] Gaestel, M., Schroeder, W., Benndorf, R., Lippman, C., Buchner, K., Hucho, F., Erdmann, V. A. and Bielka, H. (1991). Identification of the phosphorylation sites of the murine small heat shock protein hsp25. J. Biol. Chem. 266, 14721-14724.

[142] Landry, J., Lambert, H., Zhou, M., Lavoie, J. N., Hickey, E., Weber, L. A. and Anderson, C. W. (1992). Human HSP27 is phosphorylated at serines 78 and 82 by heat shock and mitogen-activated kinases that recognize the same amino acid motif as S6 kinase II. J. Biol. Chem. 267, 794-803.

[143] Stokoe, D., Engel, K., Campbell, D. G., Cohen, P. and Gaestel, M. (1992). Identification of MAPKAP kinase 2 as a major enzyme responsible for the phosphorylation of the small mammalian heat shock proteins. FEBS Lett. 313, 307313.

[144] Rouse, J., Cohen, P., Trigon, S., Morange, M., Alonso-Llamazares, A., Zamanillo, D., Hunt, T. and Nebreda, A. R. (1994). A novel kinase cascade triggered by stress and heat shock that stimulates MAPKAP kinase-2 and phosphorylation of the small heat shock proteins. Cell 78, 1027-1037.

[145] Edwards, H. V., Scott, J. D. and Baillie, G. S. (2012). PKA phosphorylation of the small heat-shock protein Hsp20 enhances its cardioprotective effects. Biochem. Soc. Trans. 40, 210-214.

[146] Fan, G. C., Chu, G. X., Mitton, B., Song, Q. J., Yuan, Q. Y. and Kranias, E. G. (2004). Small heat-shock protein Hsp20 phosphorylation inhibits $\beta$-agonist-induced cardiac apoptosis. Circ. Res. 94, 1474-1482.

[147] Beall, A., Bagwell, D., Woodrum, D., Stoming, T. A., Kato, K., Suzuki, A., Rasmussen, H. and Brophy, C. M. (1999). The small heat shock-related protein, HSP20, is phosphorylated on serine 16 during cyclic nucleotide-dependent relaxation. J. Biol. Chem. 274, 11344-11351.

[148] Shemetov, A. A., Seit-Nebi, A. S., Bukach, O. V. and Gusev, N. B. (2008). Phosphorylation by cyclic AMP-dependent protein kinase inhibits chaperone-like activity of human HSP22 in vitro. Biochemistry (Mosc). 73, 200-208.

[149] Rosales, J. L., Sarker, K., Ho, N., Broniewska, M., Wong, P., Cheng, M., van der Hoorn, F. A. and Lee, K. Y. (2007). ODF1 phosphorylation by Cdk5/p35 enhances ODF1-OIP1 interaction. Cell. Physiol. Biochem. 20,311-318.

[150] Aquilina, J. A., Benesch, J. L., Ding, L., Yaron, O., Horwitz, J. and Robinson, C. V. (2004). Phosphorylation of alphaB-crystallin alters chaperone function through loss of dimeric substructure. J. Biol. Chem. 279, 28675-28680. 
[151] Ecroyd, H., Meehan, S. M., Horwitz, J., Aquilina, J. A., Benesch, J. L. P., Robinson, C. V., MacPhee, C. E. and Carver, J. A. (2007). Mimicking phosphorylation of alphaB-crystallin affects its chaperone activity. Biochem. J. 401, 129-141.

[152] Ahmad, M. F., Raman, B., Ramakrishna, T. and Rao Ch, M. (2008). Effect of phosphorylation on alphaB-crystallin: differences in stability, subunit exchange and chaperone activity of homo and mixed oligomers of alphaB-crystallin and its phosphorylation-mimicking mutant. J. Mol. Biol. 375, 1040-1051.

[153] Rogalla, T., Ehrnsperger, M., Preville, X., Kotlyarov, A., Lutsch, G., Ducasse, C., Paul, C., Wieske, M., Arrigo, A. P., Buchner, J. and Gaestel, M. (1999). Regulation of Hsp27 oligomerization, chaperone function, and protective activity against oxidative stress/tumor necrosis factor alpha by phosphorylation. J. Biol. Chem. 274, 1894718956.

[154] Hayes, D., Napoli, V., Mazurkie, A., Stafford, W. F. and Graceffa, P. (2009). Phosphorylation dependence of hsp27 multimeric size and molecular chaperone function. J. Biol. Chem. 284, 18801-18807.

[155] Lambert, H., Charette, S. J., Bernier, A. F., Guimond, A. and Landry, J. (1999). HSP27 multimerization mediated by phosphorylation-sensitive intermolecular interactions at the amino terminus. J. Biol. Chem. 274, 9378-9385.

[156] Shashidharamurthy, R., Koteiche, H. A., Dong, J. and McHaourab, H. S. (2005). Mechanism of chaperone function in small heat shock proteins: dissociation of the HSP27 oligomer is required for recognition and binding of destabilized T4 lysozyme. J. Biol. Chem. 280, 5281-5289.

[157] Theriault, J. R., Lambert, H., Chavez-Zobel, A. T., Charest, G., Lavigne, P. and Landry, J. (2004). Essential role of the NH2-terminal WD/EPF motif in the phosphorylation-activated protective function of mammalian Hsp27. J. Biol. Chem. 279, 23463-23471.

[158] Voorter, C. E., Wintjes, L., Bloemendal, H. and de Jong, W. W. (1992). Relocalization of alphaB-crystallin by heat shock in ovarian carcinoma cells. FEBS Lett. 309, 111-114.

[159] van den Ijssel, P., Wheelock, R., Prescott, A., Russell, P. and Quinlan, R. A. (2003). Nuclear speckle localisation of the small heat shock protein alphaB-crystallin and its inhibition by the R120G cardiomyopathy-linked mutation. Exp. Cell Res. 287, 249261.

[160] Adhikari, A. S., Sridhar Rao, K., Rangaraj, N., Parnaik, V. K. and Mohan Rao, C. (2004). Heat stress-induced localization of small heat shock proteins in mouse myoblasts: intranuclear lamin A/C speckles as target for alphaB-crystallin and Hsp25. Exp. Cell Res. 299, 393-403.

[161] den Engelsman, J., Gerrits, D., de Jong, W. W., Robbins, J., Kato, K. and Boelens, W. C. (2005). Nuclear import of alphaB-crystallin is phosphorylation-dependent and hampered by hyperphosphorylation of the myopathy-related mutant R120G. J. Biol. Chem. 280, 37139-37148.

[162] Bryantsev, A. L., Chechenova, M. B. and Shelden, E. A. (2007). Recruitment of phosphorylated small heat shock protein Hsp27 to nuclear speckles without stress. Exp. Cell Res. 313, 195-209.

[163] Kamei, K., Hamaguchi, T., Matsuura, N., Iwase, H. and Masuda, K. (2000). Posttranslational modification of alphaB-crystallin of normal human lenses. Biol. Pharm. Bull. 23, 226-230.

[164] van Noort, J. M., van Veelen, P. and Hopstaken, F. (1998). Purification of the stress protein alphaB-crystallin and its differentially phosphorylated forms. J. Immunol. Methods 221, 159-168. 
[165] Kamei, A., Hamaguchi, T., Matsuura, N. and Masuda, K. (2001). Does posttranslational modification influence chaperone-like activity of alpha-crystallin? I. Study on phosphorylation. Biol. Pharm. Bull. 24, 96-9.

[166] Benesch, J. L., Ayoub, M., Robinson, C. V. and Aquilina, J. A. (2008). Small heat shock protein activity is regulated by variable oligomeric substructure. J. Biol. Chem. 283, 28513-28517.

[167] Ito, H., Kamei, K., Iwamoto, I., Inaguma, Y., Nohara, D. and Kato, K. (2001). Phosphorylation-induced change of the oligomerization state of alphaB-crystallin. J. Biol. Chem. 276, 5346-5352.

[168] den Engelsman, J., Bennink, E. J., Doerwald, L., Onnekink, C., Wunderink, L., Andley, U. P., Kato, K., de Jong, W. W. and Boelens, W. C. (2004). Mimicking phosphorylation of the small heat-shock protein alphaB-crystallin recruits the F-box protein FBX4 to nuclear SC35 speckles. Eur. J. Biochem. 271, 4195-4203.

[169] Launay, N., Tarze, A., Vicart, P. and Lilienbaum, A. (2010). Serine 59 phosphorylation of $\alpha \mathrm{B}$-crystallin down-regulates its anti-apoptotic function by binding and sequestering Bcl-2 in breast cancer cells. J. Biol. Chem. 285, 3732437332.

[170] Knauf, U., Jakob, U., Engel, K., Buchner, J. and Gaestel, M. (1994). Stress- and mitogen-induced phosphorylation of the small heat shock protein Hsp25 by MAPKAP kinase 2 is not essential for chaperone properties and cellular thermoresistance. EMBO J. 13, 54-60.

[171] Braun, N., Zacharias, M., Peschek, J., Kastenmüller, A., Zou, J., Hanzlik, M., Haslbeck, M., Rappsilber, J., Buchner, J. and Weinkauf, S. (2011). Multiple molecular architectures of the eye lens chaperone $\alpha \mathrm{B}$-crystallin elucidated by a triple hybrid approach. Proc. Natl. Acad. Sci. U. S. A. 108, 20491-20496.

[172] Clark, J. I. and Muchowski, P. J. (2000). Small heat shock proteins and their potential role in human disease. Curr. Opin. Struct. Biol. 10, 52-59.

[173] Thomas, P. J., Qu, B.-H. and Pedersen, P. L. (1995). Defective protein folding as a basis of human disease. Trends Biochem. Sci. 20, 456-459.

[174] Sun, Y. and MacRae, T. H. (2005). The small heat shock proteins and their role in human disease. FEBS J. 272, 2613-2627.

[175] Arrigo, A. P. (2005). In search of the molecular mechanism by which small stress proteins counteract apoptosis during cellular differentiation. J. Cell. Biochem. 94, 241-246.

[176] Mehlen, P., Mehlen, A., Godet, J. and Arrigo, A. P. (1997). Hsp27 as a switch between differentiation and apoptosis in murine embryonic stem cells. J. Biol. Chem. 272, 31657-31665.

[177] Gusev, N. B., Bogatcheva, N. V. and Marston, S. B. (2002). Structure and properties of small heat shock proteins ( $\mathrm{sHsp}$ ) and their interaction with cytoskeleton proteins. Biochemistry (Mosc). 67, 511-519.

[178] Mounier, N. and Arrigo, A. P. (2002). Actin cytoskeleton and small heat shock proteins: how do they interact? Cell Stress Chaperones 7, 167-176.

[179] Parcellier, A., Gurbuxani, S., Schmitt, E., Solary, E. and Garrido, C. (2003). Heat shock proteins, cellular chaperones that modulate mitochondrial cell death pathways. Biochem. Biophys. Res. Commun. 304, 505-512.

[180] Rekas, A., Adda, C. G., Aquilina, J. A., Barnham, K. J., Sunde, M., Galatis, D., Williamson, N. A., Masters, C. L., Anders, R. F., Robinson, C. V., Cappai, R. and Carver, J. A. (2004). Interaction of the molecular chaperone $\alpha B$-crystallin with $\alpha$ synuclein: Effects on amyloid fibril formation and chaperone activity. J. Mol. Biol. 340, 1167-1183. 
[181] Quinlan, R. A., Brenner, M., Goldman, J. E. and Messing, A. (2007). GFAP and its role in Alexander Disease. Exp. Cell Res. 313, 2077-2087.

[182] Anagnostou, G., Akbar, M. T., Paul, P., Angelinetta, C., Steiner, T. J. and de Belleroche, J. (2010). Vesicle associated membrane protein B (VAPB) is decreased in ALS spinal cord. Neurobiol. Aging 31, 969-985.

[183] Wilhelmus, M. M., Otte-Holler, I., Wesseling, P., de Waal, R. M., Boelens, W. C. and Verbeek, M. M. (2006). Specific association of small heat shock proteins with the pathological hallmarks of Alzheimer's disease brains. Neuropathol. Appl. Neurobiol. 32, 119-130.

[184] Crippa, V., Sau, D., Rusmini, P., Boncoraglio, A., Onesto, E., Bolzoni, E., Galbiati, M., Fontana, E., Marino, M., Carra, S., Bendotti, C., De Biasi, S. and Poletti, A. (2010). The small heat shock protein B8 (HspB8) promotes autophagic removal of misfolded proteins involved in amyotrophic lateral sclerosis (ALS). Hum. Mol. Genet. 19, 3440-3456.

[185] Seidel, K., J., V., den Dunnen, W. F. A., Brunt, E. R., Meister, M., Boncoraglio, A., Zijlstra, M. P., Boddeke, H. W. G. M., Rüb, U., Kampinga, H. H. and Carra, S. (2012). The HSPB8-BAG3 chaperone complex is upregulated in astrocytes in the human brain affected by protein aggregation diseases. Neuropathol. Appl. Neurobiol. 38, 39-53.

[186] Goldman, J. E. and Corbin, E. (1991). Rosenthal fibres contain ubiquitinated alphaBcrystallin. Am. J. Pathol. 139, 933-938.

[187] Tomokane, N., Iwaki, T., Tateishi, J., Iwaki, A. and Goldman, J. E. (1991). Rosenthal fibers share epitopes with alphaB-crystallin, glial fibrillary acidic protein, and ubiquitin, but not with vimentin. Immunoelectron microscopy with colloidal gold. Am. J. Pathol. 138, 875-885.

[188] Weissenbock, H., Obermaier, G. and Dahme, E. (1996). Alexander's disease in a Bernese mountain dog. Acta Neuropathol. (Berl). 91, 200-204.

[189] de Jong, W. W., Leunissen, J. A. and Voorter, C. E. (1993). Evolution of the alphacrystallin/small heat-shock protein family. Mol. Biol. Evol. 10, 103-126.

[190] Hershko, A., Eytan, E., Ciechanover, A. and Haas, A. L. (1982). Immunochemical analysis of the turnover of ubiquitin-protein conjugates in intact cells. Relationship to the breakdown of abnormal proteins. J. Biol. Chem. 257, 13964-13970.

[191] Kato, S., Hirano, A., Umahara, T., Llena, J. F., Herz, F. and Ohama, E. (1992). Ultrastructural and immunohistochemical studies on ballooned cortical neurons in Creutzfeldt-Jakob disease: expression of alphaB-crystallin, ubiquitin and stressresponse protein 27. Acta Neuropathol. (Berl). 84, 443-448.

[192] van Rijk, A. F. and Bloemendal, H. (2000). AlphaB-crystallin in neuropathology. Ophthalmologica 214, 7-12.

[193] Selkoe, D. J. (1994). Cell biology of the amyloid beta-protein precursor and the mechanism of Alzheimer's disease. Annual Reviews of Cell Biology 10, 373-403.

[194] Jarrett, J. T., Berger, E. P. and Lansbury, P. T. J. (1993). The C-terminus of the beta protein is critical in amyloidogenesis. Ann. N. Y. Acad. Sci. 695, 144-148.

[195] Johnston, J. A., Cowburn, R. F., Norgren, S., Wiehager, B., Venizelos, N., Winblad, B., Vigo-Pelfrey, C., Schenk, D., Lannfelt, L. and O'Neil, 1. C. (1994). Increased betaamyloid release and levels of amyloid precursor protein (APP) in fibroblast cell lines from family members with the Swedish Alzheimer's disease APP670/671 mutation. FEBS Lett. 354, 274-278.

[196] Lansbury, P. T. J. (1995). Consequences of the molecular mechanism of amyloid formation for the understanding of the pathogenesis of Alzheimer's disease and the development of therapeutic strategies. Arzneimittelforschung. 45, 432-434. 
[197] Scheuner, D., Eckman, C., Jensen, M., Song, X., Citron, M., Suzuki, N., Bird, T. D., Hardy, J., Hutton, M., Kukull, W., Larson, E., Levy-Lahad, E., Viitanen, M., Peskind, E., Poorkaj, P., Schellenberg, G., Tanzi, R., Wasco, W., Lannfelt, L., Selkoe, D. J. and S., Y. (1996). Secreted amyloid beta-protein similar to that in the senile plaques of Alzheimer's disease is increased in vivo by the presenilin 1 and 2 and APP mutations linked to familial Alzheimer's disease. Nat. Med. 2, 864-870.

[198] Iwaki, T., Wisniewski, T., Iwaki, A., Corbin, E., Tomokane, N., Tateishi, J. and Goldman, J. E. (1992). Accumulation of alphaB-crystallin in central nervous system glia and neurons in pathologic conditions. Am. J. Pathol. 140, 345-356.

[199] Dehle, F. C., Ecroyd, H., Musgrave, I. F. and Carver, J. A. (2010). AlphaB-crystallin inhibits the cell toxicity associated with amyloid fibril formation by kappa-casein and the amyloid-beta peptide. Cell Stress Chaperones 15, 1013-1026.

[200] Fändrich, M., Schmidt, M. and Grigorieff, N. (2011). Recent progress in understanding Alzheimer's $\beta$-amyloid structures. Trends Biochem. Sci. 36, 338-345.

[201] Noble, W., Hanger, D. P., Miller, C. C. and Lovestone, S. (2013). The importance of tau phosphorylation for neurodegenerative diseases. Front Neurol. 4, 83.

[202] Dabir, D. V., Trojanowski, J. Q., Richter-Landsberg, C., Lee, V. M.-Y. and Forman, M. S. (2004). Expression of the small heat-shock protein $\alpha \mathrm{B}$-crystallin in tauopathies with glial pathology. Am. J. Pathol. 164, 155-166.

[203] Sun, G., Guo, M., Shen, A., Mei, F., Peng, X., Gong, R., Guo, D., Wu, J., Tien, P. and Xiao, G. (2005). Bovine PrPC directly interacts with alphaB-crystalline. FEBS Lett. 579, 5419-5424.

[204] Tamaoka, A., Mizusawa, H., Mori, H. and Shoji, S. (1995). Ubiquitinated alphaBcrystallin in glial cytoplasmic inclusions from the brain of a patient with multiple system atrophy. J. Neurol. Sci. 129, 192-198.

[205] Yerbury, J. J., Gower, D., Vanags, L., Roberts, K., Lee, J. A. and Ecroyd, H. (2013). The small heat shock proteins $\alpha \mathrm{B}$-crystallin and Hsp27 suppress SOD1 aggregation in vitro. Cell Stress Chaperones 18, 251-257.

[206] Karch, C. M. and Borchelt, D. R. (2010). An examination of alphaB-crystallin as a modifier of SOD1 aggregate pathology and toxicity in models of familial amyotrophic lateral sclerosis. J. Neurochem. 113, 1092-1100.

[207] Cox, D., Carver, J. A. and Ecroyd, H. (2014). Preventing $\alpha$-synuclein aggregation: The role of the small heat-shock molecular chaperone proteins. Biochim. Biophys. Acta 1842, 1830-1843.

[208] Mizutani, T., Inose, T., Nakajima, S., Kakimi, S., Uchigata, M., Ikeda, K., Gambetti, P. and Takasu, T. (1998). Familial Parkinsonism and dementia with ballooned neurons, argyrophilic neuronal inclusions, atypical neurofibrillary tangles, taunegative astrocytic fibrillary tangles, and Lewy bodies. Acta Neuropathol. (Berl). 95, $15-27$.

[209] Vos, M. J., Zijlstra, M. P., Kanon, B., van Waarde-Verhagen, M. A., Brunt, E. R., Oosterveld-Hut, H. M., Carra, S., Sibon, O. C. and Kampinga, H. H. (2010). HSPB7 is the most potent polyQ aggregation suppressor within the HSPB family of molecular chaperones. Hum. Mol. Genet. 19, 4677-4693.

[210] Robertson, A. L., Headey, S. J., Saunders, H. M., Ecroyd, H., Scanlon, M. J., Carver, J. A. and Bottomley, S. P. (2010). Small heat-shock proteins interact with a flanking domain to suppress polyglutamine aggregation. Proc. Natl. Acad. Sci. U. S. A. 107, 10424-10429

[211] Han, M. H., Hwang, S. I., Roy, D. B., Lundgren, D. H., Price, J. V., Ousman, S. S., Fernald, G. H., Gerlitz, B., Robinson, W. H., Baranzini, S. E., Grinnell, B. W., Raine, 
C. S., Sobel, R. A., Han, D. K. and Steinman, L. (2008). Proteomic analysis of active multiple sclerosis lesions reveals therapeutic targets. Nature 451, 1076-1081.

[212] Chabas, D., Baranzini, S. E., Mitchell, D., Bernard, C. C., Rittling, S. R., Denhardt, D. T., Sobel, R. A., Lock, C., Karpuj, M., Pedotti, R., Heller, R., Oksenberg, J. R. and Steinman, L. (2001). The influence of the proinflammatory cytokine, osteopontin, on autoimmune demyelinating disease. Science 294, 1731-1735.

[213] van Noort, J. M., van Sechel, A. C., van Stipdonk, M. J. B. and Bajramovic, J. (1997) The small heat shock protein $\alpha \mathrm{B}$-crystallin as a key autoantigen in multiple sclerosis. In 20th International Summer School of Brain Research (van Leeuwen, F.W., Salehi, A., Giger, R.J., Holtmaat, A.J.G.D. and Verhaagen, J., ed.^eds), pp. 435-452.

Elsevier, Royal Netherlands Academy of Sciences, Amsterdam, The Netherlands.

[214] Rothbard, J. B., Zhao, X., Sharpe, O., Strohman, M. J., Kurnellas, M., Mellins, E. D., Robinson, W. H. and Steinman, L. (2011). Chaperone activity of $\alpha B$-crystallin is responsible for its incorrect assignment as an autoantigen in multiple sclerosis. J. Immunol. 186, 4263-4268.

[215] Chen, P., Ji, W., Liu, F. Y., Tang, H. Z., Fu, S., Zhang, X., Liu, M., Gong, L., Deng, M., Hu, W. F., Hu, X. H., Chen, X. W., Li, Z. L., Li, X., Liu, J. and Li, D. W. (2012). Alpha-crystallins and tumorigenesis. Curr. Mol. Med. 12, 1164-1173.

[216] Xu, L., Chen, S. and Bergan, R. C. (2006). MAPKAPK2 and HSP27 are downstream effectors of p38 MAP kinase-mediated matrix metalloproteinase type 2 activation and cell invasion in human prostate cancer. Oncogene 25, 2987-2998.

[217] Moyano, J. V., Evans, J. R., Chen, F., Lu, M., Werner, M. E., Yehiely, F., Diaz, L. K., Turbin, D., Karaca, G., Wiley, E., Nielsen, T. O., Perou, C. M. and Cryns, V. L. (2006). AlphaB-crystallin is a novel oncoprotein that predicts poor clinical outcome in breast cancer. J. Clin. Invest. 116, 261-270.

[218] Oesterreich, S., Weng, C. N., Qiu, M., Hilsenbeck, S. G., Osborne, C. K. and Fuqua, S. A. (1993). The small heat shock protein hsp27 is correlated with growth and drug resistance in human breast cancer cell lines. Cancer Res. 53, 4443-4448.

[219] Webster, K. A. (2003). Serine phosphorylation and suppression of apoptosis by the small heat-shock protein alphaB-crystallin. Circ. Res. 92, 130-132.

[220] Mao, Y.-W., Liu, J.-P., Xiang, H. and Li, D.-C. (2004). Human alphaA- and alphaBcrystallins bind to Bax and Bcl-XS to sequester their translocation during staurosporine-induced apoptosis. Cell Death Differ. 11, 512-526.

[221] Charette, S. J., Lavoie, J. N., Lambert, H. and Landry, J. (2000). Inhibition of Daxxmediated apoptosis by Heat Shock Protein 27. Mol. Cell. Biol. 20, 7602-7612.

[222] Mehlen, P., Schulze-Osthoff, K. and Arrigo, A. P. (1996). Small stress proteins as novel regulators of apoptosis. Heat shock protein 27 blocks Fas/APO-1 and staurosporine-induced cell death. J. Biol. Chem. 271, 16510-16514.

[223] Vicart, P., Caron, A., Guicheney, P., Li, Z., Prevost, M.-C., Faure, A., Chateau, D., Chapon, F., Tome, F., Dupret, J.-M., Paulin, D. and Fardeau, M. (1998). A missense mutation in the alphaB-crystallin chaperone gene causes desmin-related myopathy. Nat. Genet. 20, 92-95.

[224] Xiao, X.-J. and Benjamin, I. J. (1999). Stress-response proteins in cardiovascular disease. Am. J. Hum. Genet. 64, 685-690.

[225] Olive, M., Goldfarb, L., Moreno, D., Laforet, E., Dagvadorj, A., Sambuughin, N., Martínez-Matos, J. A., Martínez, F., Alió, J., Farrero, E., Vicart, P. and Ferrer, I. (2004). Desmin-related myopathy: clinical, electrophysiological, radiological, neuropathological and genetic studies. J. Neurol. Sci. 219, 125-137.

[226] Chavez Zobel, A. T., Lornager, A., Marceau, N., Theriault, J. R., Lambert, H. and Landry, J. (2003). Distinct chaperone mechanisms can delay the formation of 
aggresomes by the myopathy-causing R120G alphaB-crystallin mutant. Hum. Mol. Genet. 12, 1609-1620.

[227] Bova, M. P., Yaron, O., Huang, Q. L., Ding, L., Haley, D. A., Stewart, P. L. and Horwitz, J. (1999). Mutation R120G in alphaB-crystallin, which is linked to a desminrelated myopathy, results in an irregular structure and defective chaperone-like function. Proc. Natl. Acad. Sci. U. S. A. 96, 6137-6142.

[228] Treweek, T. M., Rekas, A., Lindner, R. A., Walker, M. J., Aquilina, J. A., Robinson, C. V., Horwitz, J., Perng, M. D., Quinlan, R. A. and Carver, J. A. (2005). R120G alphaB-crystallin promotes the unfolding of reduced alpha-lactalbumin and is inherently unstable. FEBS J. 272, 711-724.

[229] Berry, V., Francis, P., Reddy, M. A., Collyer, D., Vithana, E., MacKay, I., Dawson, G., Carey, A. H., Moore, A., Bhattacharya, S. S. and Quinlan, R. A. (2001). AlphaBcrystallin gene (CRYAB) mutation causes dominant congenital posterior polar cataract. Am. J. Hum. Genet. 69, 1141-1145.

[230] Liu, Y., Zhang, X., Luo, L., Wu, M., Zeng, R., Cheng, G., Hu, B., Liu, B., Liang, J. J. and Shang, F. (2006). A novel alphaB-crystallin mutation associated with autosomal dominant congenital lamellar cataract. Invest. Ophthalmol. Vis. Sci. 47, 1069-1075.

[231] Litt, M., Kramer, P., LaMorticella, D. M., Murphey, W., Lovrien, E. W. and Weleber, R. G. (1998). Autosomal dominant congenital cataract associated with a missense mutation in the human alpha-crystallin gene CRYAA. Hum. Mol. Genet. 7, 471-474.

[232] Graw, J., Loster, J., Soewarto, D., Fuchs, H., Meyer, B., Reis, A., Wolf, E., Balling, R. and Hrabe de Anglis, M. (2001). Characterization of a new, dominant V124E mutation in the mouse alphaA-crystallin-encoding gene. Invest. Ophthalmol. Vis. Sci. 42, 2909-2915.

[233] Shroff, N. P., Cherian-Shaw, M., Bera, S. and Abraham, E. C. (2000). Mutation of R116C results in highly oligomerized alphaA-crystallin with modified structure and defective chaperone-like function. Biochemistry (Mosc). 39, 1420-1426.

[234] Kumar, L. V. S., Ramakrishna, T. and Rao, C. M. (1999). Structural and functional consequences of the mutations of a conserved arginine residue in alphaA- and alphaBcrystallins. J. Biol. Chem. 274, 24137-24141.

[235] Bera, S. and Abraham, E. C. (2002). The alphaA-crystallin R116C mutant has a higher affinity for forming heteroaggregates with alphaB-crystallin. Biochemistry (Mosc). 41, 297-305.

[236] Berengian, A. R., Bova, M. P. and Mchaourab, H. S. (1997). Structure and function of the conserved domain in alphaA-crystallin. Site-directed spin labeling identifies a beta-strand located near a subunit interface. Biochemistry (Mosc). 36, 9951-9957.

[237] Gu, F., Luo, W., Li, X., Wang, Z., Lu, S., Zhang, M., Zhao, B., Zhu, S., Feng, S., Yan, Y., Huang, S. and Ma, X. (2008). A novel mutation in alphaA-crystallin (CRYAA) caused autosomal dominant congenital cataract in a large Chinese family. Hum. Mutat. 29, 769-769.

[238] Andley, U. P., Patel, H. C. and Xi, J.-H. (2002). The R116C mutation in alphaAcrystallin diminishes its protective ability against stress-induced lens epithelial cell apoptosis. J. Biol. Chem. 277, 10178-10186.

[239] Santhiya, S. T., Söker, T., Klopp, N., Illig, T., Prakash, M. V. S., Selvaraj, B., Gopinath, P. M. and Graw, J. (2006). Identification of a novel, putative cataractcausing allele in CRYAA (G98R) in an Indian family. Mol. Vis. 12, 768-773.

[240] Xia, C., Liu, H., Chang, B., Cheng, C., Cheung, D., Wang, M., Huang, Q. L., Horwitz, J. and Gong, X. (2006). Arginine 54 and tyrosine 118 residues of $\alpha$ Acrystallin are crucial for lens formation and transparency. Invest. Ophthalmol. Vis. Sci. 47, 3004-3010. 
[241] Evgrafov, O. V., Mersiyanova, I., Irobi, J., Van Den Bosch, L., Dierick, I., Leung, C. L., Schagina, O., Verpoorten, N., Van Impe, K., Fedotov, V., Dadali, E., AuerGrumbach, M., Windpassinger, C., Wagner, K., Mitrovic, Z., Hilton-Jones, D., Talbot, K., Martin, J. J., Vasserman, N., Tverskaya, S., Polyakov, A., Liem, R. K., Gettemans, J., Robberecht, W., De Jonghe, P. and Timmerman, V. (2004). Mutant small heat-shock protein 27 causes axonal Charcot-Marie-Tooth disease and distal hereditary motor neuropathy. Nat. Genet. 36, 602-606.

[242] Fontaine, J.-M., Sun, X., Hoppe, A. D., Simon, S., Vicart, P., Welsh, M. J. and Benndorf, R. (2006). Abnormal small heat shock protein interactions involving neuropathy-associated HSP22 (HSPB8) mutants. FASEB J. 20, 2168-2171.

[243] Nakhro, K., Park, J.-M., Kim, Y. J., Yoon, B. R., Yoo, J. H., Koo, H., Choi, B.-O. and Chung, K. W. (2013). A novel Lys141Thr mutation in small heat shock protein 22 (HSPB8) gene in Charcot-Marie-Tooth disease type 2L. Neuromuscul. Disord. 23, 656-663.

[244] Irobi, J., Van Impe, K., Seeman, P., Jordanova, A., Dierick, I., Verpoorten, N., Michalik, A., De Vriendt, E., Jacobs, A., Van Gerwen, V., Vennekens, K., Mazanec, R., Tournev, J., Broeckhoven, J., Gettemans, J., De Jonghe, P. and Timmerman, V. (2004). Hot-spot residue in small heat-shock protein 22 causes distal motor neuropathy. Nat. Genet. 36, 597-601.

[245] Tang, B., Zhao, G., Luo, W., Xia, K., Cai, F., Pan, Q., Zhang, R., Zhang, F., Jiang, H., Long, Z. and Dai, H. (2005). Small heat-shock protein 22 mutated in autosomal dominant Charcot-Marie-Tooth disease type 2L. Hum. Genet. 116, 222-224.

[246] Houlden, H., M. Laura, M., Wavrant-De Vrièze, F., Blake, J., Wood, N. and Reilly, M. M. (2008). Mutations in the HSP27 (HSPB1) gene cause dominant, recessive, and sporadic distal HMN/CMT type 2. Neurology 71, 1660-1668.

[247] Ikeda, Y., Abe, A., Ishida, C., Takahashi, K., Hayasaka, K. and Yamada, M. (2009). A clinical phenotype of distal hereditary motor neuronopathy type II with a novel HSPB1 mutation. J. Neurol. Sci. 277, 9-12.

[248] Inagaki, N., Hayashi, T., Arimura, T., Koga, Y., Takahashi, M., Shibata, H., Teraoka, K., Chikamori, T., Yamashina, A. and Kimura, A. (2006). alphaB-Crystallin mutation in dilated cardiomyopathy. Biochem. Biophys. Res. Commun. 342, 379-386.

[249] Pilotto, A., Marziliano, N., Pasotti, M., Grasso, M., Costante, A. M. and Arbustini, E. (2006). alphaB-Crystallin mutation in dilated cardiomyopathies: Low prevalence in a consecutive series of 200 unrelated probands. Biochem. Biophys. Res. Commun. 346, 1115-1117.

[250] Selcen, D. and Engel, A. G. (2003). Myofibrillar myopathy caused by dominant negative alphaB-crystallin mutations. Ann. Neurol. 54, 804-810.

[251] Luigetti, M., Fabrizi, G. M., Madia, F., Ferrarini, M., Conte, A., Del Grande, A., Tasca, G., Tonali, P. A. and Sabatelli, M. (2010). A novel HSPB1 mutation in an Italian patient with CMT2/dHMN phenotype. Journal of Neurological Sciences 298, 114-117.

[252] Kijima, K., Numakura, C., Goto, T., Takahashi, T., Otagiri, T., Umetsu, K. and Hayasaka, K. (2005). Small heat shock protein 27 mutation in a Japanese patient with distal hereditary motor neuropathy. J. Hum. Genet. 50, 473-476.

[253] Del Bigio, M. R., Chudley, A. E., Sarnat, H. B., Campbell, C., Goobie, S., Chodirker, B. N. and Selcen, D. (2011). Infantile muscular dystrophy in Canadian aboriginals is an $\alpha B$-crystallinopathy. Ann. Neurol. 69, 866-871.

[254] de Jong, W. W., Caspers, G. J. and Leunissen, J. A. (1998). Genealogy of the alphacrystallin-small heat-shock protein superfamily. Int. J. Biol. Macromol. 22, 151-162. 
[255] Li, H., Lu, Q., Su, Q., Su, T., Li, D., Yuan, M., Liu, J., Ren, X., Zhang, Z., Zeng, S., Wang, Q. and Liu, M. (2008). Cataract mutation P20S of $\alpha$ B-crystallin impairs chaperone activity of $\alpha \mathrm{A}$-crystallin and induced apoptosis of human lens epithelial cells. Biochim. Biophys. Acta 1782, 303-309.

[256] Mackay, D. S., Andley, U. P. and Sheils, A. (2003). Cell death triggered by a novel mutation in the alphaA-crystallin gene underlies autosomal dominant cataract linked to chromosome 21q. Eur. J. Hum. Genet. 11, 784-793.

[257] Pras, E., Frydman, M., Levy-Nissenbaum, E., Bakhan, T., Raz, J., Assia, E. I., Goldman, B. and Pras, E. (2000). A nonsense mutation (W9X) in CRYAA causes autosomal recessive cataract in an inbred Jewish Persian family. Invest. Ophthalmol. Vis. Sci. 41, 3511-3515.

[258] Graw, J., Klopp, N., Illig, T., Preising, M. N. and Lorenz, B. (2006). Congenital cataract and macular hypoplasia in humans associated with a de novo mutation in CRYAA and compound heterozygous mutations in P. Graefes Arch. Clin. Exp. Ophthalmol. 244, 912-919.

[259] Hansen, L., Yao, W., Eiberg, H., Kjaer, K. W., Baggesen, K., Hejtmancik, J. F. and Rosenberg, T. (2007). Genetic heterogeneity in microcornea-cataract: five novel mutations in CRYAA, CRYGD, and GJA8. Invest. Ophthalmol. Vis. Sci. 48, 39373944.

[260] Devi, R. R., Yao, W., Vijayalakshmi, P., Sergeev, Y. V., Sundaresan, P. and Hejtmancik, J. F. (2008). Crystallin gene mutations in Indian families with inherited pediatric cataract. Mol. Vis. 14, 1157-1170.

[261] Bose, S., Ehrnsperger, M. and Buchner, J. (1999) Mechanisms of ATP-independent vs ATP-dependent chaperones. In Molecular chaperones and folding catalysts:Regulation, function and mechanisms. (Bukau, B., ed.^eds), pp. 637-660. Harwood Academic Pub., Amsterdam.

[262] Richter, L., Flodman, P., von-Bischhoffshausen, F. B., Burch, D., Brown, S., Nguyen, L., Turner, J., Spence, M. A. and Bateman, J. B. (2008). Clinical variability of autosomal dominant cataract, microcornea and corneal opacity and novel mutation in the alphaA-crystallin gene (CRYAA). Am. J. Med. Genet. 146, 833-842.

[263] Safieh, L. A., Khan, A. O. and Alkuraya, F. S. (2009). Identification of a novel CRYAB mutation associated with autosomal recessive juvenile cataract in a Saudi family. Mol. Vis. 15, 980-984.

[264] Ghosh, J. G., Estrada, M. R. and Clark, J. I. (2005). Interactive domains for chaperone activity in the small heat shock protein, human alphaB-crystallin. Biochemistry (Mosc). 44, 14854-14869. 